\title{
Production and characterization of the maximum liquid product obtained from co-pyrolysis of sugarcane bagasse and thermocol waste
}

Sowhm Swain Mohapatra ( $\nabla$ sowhmsmohapatra@gmail.com )

National Institute of Technology Rourkela https://orcid.org/0000-0001-9819-551X

Raghubansh Kumar Singh

National Institute of Technology Rourkela

\section{Original Research}

Keywords: Co-pyrolysis, Sugarcane bagasse, Thermocol waste, Aromatic compounds

Posted Date: February 17th, 2021

DOl: https://doi.org/10.21203/rs.3.rs-184413/v1

License: (c) (1) This work is licensed under a Creative Commons Attribution 4.0 International License. Read Full License

Version of Record: A version of this preprint was published at Cellulose on March 3rd, 2021. See the published version at https://doi.org/10.1007/s10570-021-03775-0. 


\section{Abstract}

The current study explores co-pyrolysis of sugarcane bagasse, and thermocol waste in a semi-batch reactor to evaluate the influence of temperature, and blending ratio on yield of products, and reaction time, and thereby characterize the maximum liquid product. The properties of liquid product (bio-oil), and the solid product (bio-char) obtained from thermal sugarcane bagasse, and co-pyrolysis sugarcane bagasse: thermocol waste bio-oil were investigated for physicochemical characterizations. The compositional analysis result of the co-pyrolysis liquid product established the presence of several aromatic compounds. The co-pyrolysis liquid product manifested a higher calorific value, carbon, and hydrogen content as compared to sugarcane bagasse thermal pyrolysis bio-oil. The co-pyrolysis liquid product can be used as a liquid fuel in internal combustion engines, as well as a precursor for valueadded chemicals. The properties of bio-char suggested it can be used as a solid fuel, as well as an adsorbent.

\section{Introduction}

With excel in the world's population, the energy plea is increasing rapidly and it is mainly satiated by fossil fuel sources. However, due to the surge in the consumption of fossil fuel create an energy crisis and environmental sustainability problems. Therefore, alternate energy sources like solar, hydroelectric, wind and biomass, etc., play an active role to improve energy security as well as mitigate the environmental pollution caused by fossil fuel sources. Further, the use of carbon-neutral and low emission fuel sources like biomass has gained the attention of several researchers all over the world. Further, it is also estimated by the International Energy Agency that biomass has prospective to meet around $10 \%$ of world energy demand by 2035 , and the biofuels produced from biomass will fulfill around $27 \%$ of world transportation fuels by 2050 ( Shurong et al. 2017).

In general, biomass can be transformed into biofuels in three ways such as thermochemical, biological, and physical conversion processes. The thermochemical conversion process comprises combustion, pyrolysis, gasification, and liquefaction respectively. Among these, pyrolysis has expanded much consideration since it converts the biomass/waste into high dense energy products (Goyal, Seal, and Saxena 2008; Nanda, Mohammad, and Reddy 2014). Apart from biomass, several other waste residues are also generated in the society in the form of waste plastics and tires, which are either incinerated or deposited in landfills. The valorization of wastes (biomass, and plastics) is a great topic of concern for many researchers. Pyrolysis involves the thermal degradation of any waste into smaller molecules within the temperature range of 300 to $600^{\circ} \mathrm{C}$ in absence of oxygen to produce bio-oil, bio-char, and noncondensables (Paradela et al. 2009; Bhattacharya et al. 2009; Lam et al. 2016). However, there are some disadvantages associated with the application of bio-oil due to the presence of oxygenated compounds (aldehydes, ketones, acids, alcohols, and ethers), acidic nature, low calorific value, and instability; which renders it suitability for direct utilization as a fuel in internal combustion engines (Hassan, Lim, and Hameed 2016). Therefore, to improve the properties of bio-oil, several upgradation techniques are adopted by many researchers such as hydrodeoxygenation (HDO), catalytic cracking, emulsification, etc., 
but these techniques are very complex and costly (Uzoejinwa. 2018). The co-pyrolysis of biomass and waste plastic is a viable substitute for the generation of high quality bio-oil, as it is simple in operation and required low operating cost. Furthermore, it helps to reduce the wastes generated in society, which are either dump or incinerated, which leads to land/air pollution Abnisa and Wan Daud (2014). Further, the co-pyrolysis of biomass with waste plastic added the synergistic effect which improves the properties of pyrolysis products.

Sugarcane bagasse (SB) is considered as an important agroindustrial by-product of the sugar industry and is generated in abundance. Out of the total bagasse produced in the sugar industries, some of them are used in the boilers inside the plants, and used in the construction of buildings by mixing with cement (Pandey et al. 2000). In general, SB comprises a good amount of cellulose, hemicellulose, some lignin, and extractives. The thermal pyrolysis of SB is extensively studied by some researchers using different reactors, and reaction conditions to optimize the yield of (Asadullah et al. 2007; Islam, Parveen, and Haniu 2010; Varma and Mondal 2016; Morais et al. 2017). The co-feed used i.e., thermocol waste (TW) which is expanded polystyrene, is produced on large scale in India due to multipurpose applications like packaging, production of disposable trays, cups, and in insulation of floors, and roofs, etc. However, the large scale consumption has led to concern for its disposal, and reuse. The waste thermocol generated are generally used for producing value-added chemicals, in construction purpose, and production of adhesives. (Naidu, Dinda, and Radhika 2020). The co-pyrolysis of biomass and thermocol waste is reported by some researchers (Shadangi and Mohanty 2014) conducted co-pyrolysis of mahua seed and waste polystyrene (thermocol) in a semi-batch reactor and found an maximum co-pyrolytic bio-oil yield of $71.74 \%$ at a $1: 1$ blending ratio of mahua seed: polystyrene. (Shadangi and Mohanty 2015a) conducted co-pyrolysis of karanja and niger seed with waste polystyrene (thermocol) using a semi-batch reactor, and found that 2:1 blending ratio of mahua seed: polystyrene produced liquid product with the highest calorific value. Moreover, the viscosity of the liquid product was reduced with an increase in the amount of mahua seed in the blend. (Pradhan et al. 2020), wherein co-pyrolysis of mahua seed and waste thermocol was carried out using a semi-batch reactor at 1:1 ratio of mahua seed: polystyrene blend within temperature ranges of $\left(450-600^{\circ} \mathrm{C}\right)$, manifesting an maximum bio-oil yield of about $74.2 \%$ at $525^{\circ} \mathrm{C}$.

In our study, the co-pyrolysis of SB and TW is performed using a semi-batch reactor to evaluate the effect of temperature and blending ratio on yield of products and reaction time respectively. Moreover, the detailed physicochemical characterization of the bio-oil and bio-char obtained from thermal SB pyrolysis and co-pyrolysis SB: TW was carried out. There has not been any studied reported in the literature on copyrolysis of SB, and TW, involving detailed characterization of the maximum co-pyrolysis liquid as well as solid biochar.

\section{Experimental Section}

\subsection{Raw materials}


SB and TW are the raw feedstocks used in our co-pyrolysis study. SB was obtained from Sakthi Sugars, Dhenkanal, Odisha, and thermocol waste were collected from the institute premises of NIT Rourkela, Odisha. Prior analysis, SB was sun-dried and subjected to oven drying conditions, whereas the thermocol waste was first ground to powder form using a shredder. Both the feedstock samples were subjected to oven drying at $80^{\circ} \mathrm{C}$.

\subsection{Methods of Characterization}

\subsubsection{Physicochemical characterization of feedstocks, bio-oil, and bio-char}

The feedstocks (SB and TW), bio-oil, and biochar were characterized using physicochemical properties and spectroscopic techniques. The proximate analysis was conducted to determine the moisture, volatile matter, ash, and fixed carbon content adhering to ASTM D3172-07. The ultimate analysis of SB, TW, biooil, and bio-chars was done to determine the carbon, hydrogen, nitrogen, and sulfur content in the sample in percentage using a CHNS analyzer (Variael cube), wherein the oxygen content was determined by material balance. The higher heating value of the samples (SB, TW, bio-oil, and biochar) was determined using a (Parr 6100) calorimeter. The lignocellulosic analysis of SB was done to determine the cellulose, hemicellulose, lignin, and extractives content, agreeing to the procedure outlined by (Varma and Mondal 2016).

TGA was conducted in a thermogravimetric analyzer (DTG-60 series, TOSHVIN) to determine the thermal decomposition characteristics of feedstocks. The TGA analysis of SB, TW, and SB: TW blend at a ratio of $1: 1$ was conducted from room temperature to $800^{\circ} \mathrm{C}$ at $10^{\circ} \mathrm{C} / \mathrm{min}$ under inert nitrogen vicinity with a flow rate of $100 \mathrm{ml} / \mathrm{min}$.

The top organic fraction and the bottom aqueous phase was segregated via centrifugation at $1200 \mathrm{rpm}$ for 20 min followed by decantation, the top fraction is separated and sent for the characterization of physicochemical properties. The $\mathrm{pH}$ of the bio-oil and bio-char was determined using a pH meter (Orion 3 star benchtop) to determine the acidic or alkaline nature of the bio-oil. For biochar, $\mathrm{pH}$ was measured by dissolving the bio-char in distilled water at a bio-char and distilled water ratio of 1:100. The density of the bio-oil was measured using a pycnometer of $100 \mathrm{ml}$ capacity according to the procedure outlined by (Dewangan, Pradhan, and Singh 2016a). The water present in the bio-oil was determined using a dean and stark apparatus adhering to (ASTM D95-83), flash point (ASTM D92) was measured using a pensky martin flash point apparatus, pour point (ASTM D97) using a pour point apparatus, kinematic viscosity (ASTM D445) using a redwood viscometer, condrasons carbon residue by (ASTM D189). FT-IR spectrum of the products was obtained to ascertain the functional group using a (NAJO MULL) spectrophotometer within 400-4000 $\mathrm{cm}^{-1}$. GC-MS analysis was executed in a GC analyzer (Agilent 7890B) equipped with a mass spectroscopy detector to enumerate the compounds existing in the bio-oil. A DB5 MS column of 30 $\mathrm{m}$ length, $0.25 \mathrm{~mm}$ diameter was used into which about $1 \mu \mathrm{l}$ of bio-oil was inserted, and helium gas was used as the carrier gas at a flow rate of $1.5 \mathrm{ml} / \mathrm{min}$. The $\mathrm{GC}$ column was initially set at $70^{\circ} \mathrm{C}$ for $3 \mathrm{~min}$ and then augmented to $300^{\circ} \mathrm{C}$ at the heating rate of $10^{\circ} \mathrm{C} / \mathrm{min}$ for $25 \mathrm{~min}$. The ionization of the compounds 
occurred at $70 \mathrm{eV}$, an ion source temperature of $230^{\circ} \mathrm{C}$, and a mass/charge ratio range of $40-700$. The compounds were detected in chromatograms by comparing them with the NIST library database. ${ }^{1} \mathrm{H}-\mathrm{NMR}$ spectra of bio-oil was obtained by using (BRUKER, DPX 400) spectrophotometer at $500 \mathrm{MHz}$ by dissolving bio-oil in DMSO- $\mathrm{d}_{6}$ deuterated solvent obtained from Sigma Aldrich. The morphology of the bio-char was analyzed by a scanning electron microscope (NOVA NANO, SEM 450).

\subsection{Experimental Setup}

The experimental setup comprised of a cylindrical reactor, a liebig condenser, an electric furnace, a nitrogen cylinder, and a measuring cylinder respectively. The pictorial manifestation of the experimental setup is portrayed in Fig.1. The semi-batch reactor is fabricated using stainless steel 316 having a capacity of $300 \mathrm{ml}$. The furnace was heated using an electric furnace having $2 \mathrm{~kW}$ power, connected to a $\mathrm{K}$-type thermocouple, and a PID controller to modulate the temperature of the furnace. The reactor contained two openings, one for the purging of nitrogen $\left(\mathrm{N}_{2}\right)$ and another for eliminating the volatiles from the reactor, which was in turn connected with a liebig glass condenser. The condenser was supplied with ice-cooled water to condense the condensable vapors to liquid products. Before experimentation, the reactor was packed with about $20 \mathrm{~g}$ of feedstock, and purged with nitrogen gas to create an inert vicinity. The condensed liquid product was collected using a graduated measuring cylinder and thereafter stored in glass borosilicate bottles to avoid the contact of moisture. The biochar was collected only after the reactor is cooled and stored in a desiccator to avoid it from moisture contact.

\subsection{Experimental Procedure}

The initial step involves the thermal pyrolysis of SB within $\left(400-600^{\circ} \mathrm{C}\right)$ to establish the maximum temperature for maximum bio-oil yield. In the next step, the co-pyrolysis of SB, and TW was executed at an maximum temperature of $550^{\circ} \mathrm{C}$ at varying blending ratios of SB: TW as 1:0, 1:1, 1:3, 3:1, and 0:1 respectively. The yield of the products are calculated according to the Equations (1-3) given below as

Bio-oil yield $($ wt.\%) $=$ Amount of bio-oil obtained/Total feed taken

Bio-char yield $($ wt. \%) $=$ Amount of bio-char obtained/Total feed taken

Non-condensable yield $(w t . \%)=100-($ bio-oil yield + bio-char yield $)$

All the above experiments were conducted twice to obtain an accuracy in the yield of products.

\section{Results And Discussions}

\subsection{Characterization of feedstocks}


The outcome of the proximate, ultimate analysis, and higher heating value for SB and TW is manifested in Table 1. The proximate composition results established that the volatile matter for SB and TW to be 80.20 and 94.28 wt.\%; ash content of 3.10 and $0.79 \mathrm{wt} . \%$; and fixed carbon content of 11.30 and 4.68 $w t . \%$, respectively. The high volatile matter results in high liquid product yield (Vasu et al. 2019). The elemental analysis results for SB and TW showed the carbon content of 44.86 and 90.10 wt.\%; hydrogen content of 5.87 and $8.68 \mathrm{wt} . \%$; oxygen content of 48.97 and 1.21 wt.\%; $\mathrm{N}$ content of 0.24 and $0.01 \mathrm{wt} . \%$, respectively with S content in SB of $0.06 \mathrm{wt}$. \% and no sulfur present in TW. The compositional analysis of SB showed that the cellulose, hemicellulose, lignin content of $47.6,39,11.2 \mathrm{wt} \%$, respectively with extractives of $2.2 \mathrm{wt} \%$. The HHV values of SB and TW were found to be 18 and $40.25 \mathrm{MJ} / \mathrm{kg}$, respectively. The low HHV of SB is owing to high O content, however, the high HHV in the case of TW is mostly attributed to less oxygen content in the TW sample.

Table. 1 Properties of Sugarcane bagasse (SB), and Thermocol waste (TW) 


\begin{tabular}{|lll|}
\hline Proximate Analysis (wt.\%) & $\begin{array}{l}\text { Sugarcane Bagasse } \\
(\mathrm{SB}) \text { (Varma et al., 2016) }\end{array}$ & Thermocol waste (TW) \\
\hline Moisture & 5.4 & 0.25 \\
\hline Volatile Matter & 80.20 & 98.24 \\
\hline Ash & 3.10 & 0.99 \\
\hline Fixed Carbon & & 0.52 \\
\hline Ultimate Analysis (wt.\%) & 11.3 & \\
\hline Carbon & 44.86 & 90.10 \\
\hline Hydrogen & 5.87 & 8.68 \\
\hline Nitrogen & 0.24 & 0.01 \\
\hline Sulfur & 0.06 & - \\
\hline Oxygen & & 1.21 \\
\hline H/C & 48.97 & 1.01 \\
\hline O/C & 1.57 & 0.063 \\
\hline Empirical Formula & 0.82 & $\mathrm{CH}_{1.01} \mathrm{O}_{0.06}$ \\
\hline Cellulose & $\mathrm{CH}_{1.57} \mathrm{O}_{0.82}$ & - \\
\hline Hemicellulose & 47.6 & - \\
\hline Lignin & 39 & - \\
\hline Extractives & 11.2 & 40.25 \\
\hline Higher heating value, $(\mathrm{MJ} / \mathrm{kg})$ & 2.2 & \\
\hline
\end{tabular}

* By difference

\subsection{Thermogravimetric analysis of SB, TW, and SB: TW blend}

The thermal degradation curves of SB, TW, and its blend i.e., SB: TW at $(1: 1)$, and $10^{\circ} \mathrm{C} / \mathrm{min}$ are displayed in Fig. 2. It can be seen that, SB sample undergoes three fundamental stages during thermal degradation, which includes drying, devolatilization, and char formation respectively. In the first stage, temperature range up to $200^{\circ} \mathrm{C}$ around $10 \%$ mass loss occurs, which represents the elimination of moisture and low molecular weight compounds. The second stage of degradation, begins at $200^{\circ} \mathrm{C}$ gets accomplished at $450^{\circ} \mathrm{C}$, manifesting a mass loss of $68 \%$. The stage indicated thermal degradation of hemicellulose, 
cellulose, and lignin known as the active pyrolysis zone. The third stage of degradation was found between $\left(500\right.$ to $\left.800^{\circ} \mathrm{C}\right)$, where the conversion of SB into solid, carbon residue (char) takes place. In this step, 15\% mass loss occurs, which is primarily due to the degradation of lignin. After $500^{\circ} \mathrm{C}$, the degradation shows a constant straight line signifies a decrease in the rate of degradation of the lignin component and is termed as a passive pyrolysis zone Dewangan, Pradhan, and Singh (2016a). However, after the complete degradation of SB at a temperature of $800{ }^{\circ} \mathrm{C}$, about $20 \%$ solid residue is left which indicates the occurrence of fixed carbon, and some ash in the sample.

TG curve of TW showed that major mass loss occurs in a single step because plastics have the lack of natural water and the structure of plastics are not as complex as biomass (Çepelioğullar and Pütün 2013). From Fig. 2, It is observed that the degradation of TW starts at around $350^{\circ} \mathrm{C}$ and is complete at around $550{ }^{\circ} \mathrm{C}$, the mass loss of around $96 \%$ occurred in this single step and it is designated as the active pyrolysis zone for TW. However, the residual mass was found to be around $2 \%$ at temperature upto 800 ${ }^{\circ} \mathrm{C}$ and this result is also verified by the other reported literature (Özsin, Pütün, and Pütün 2019; Nisar et al. 2019).

It was observed from Fig. 2, that the mass loss of SB: TW blend consists of three stages. From the TG curve, it is seen that around $6 \%$ of mass loss occured upto $200^{\circ} \mathrm{C}$, which signifies the removal of moisture and light volatile from the blend. Further, the first mass loss stage obtained between $\left(200-350^{\circ} \mathrm{C}\right)$, wherein about $30 \%$ of mass loss occurs in this stage, which corresponds to the decomposition of holocellulose present in SB. The second stage of degradation initiates at about $360^{\circ} \mathrm{C}$ and stops degrading at $550^{\circ} \mathrm{C}$ indicated by a straight line thereafter, wherein a major mass loss of around $58 \%$ takes place, which is attributed to the decomposition of leftover cellulose, some TW components, and lignin in the blend. The third stage occurs from $\left(550-800^{\circ} \mathrm{C}\right)$, with a low mass loss of around $5 \%$ corresponds to the decomposition of lignin. It is because, during co-pyrolysis of SB, and TW because of hydrogen transfer from TW to SB radicals, which stabilizes the products obtained from cellulose thermal degradation (Mishra and Mohanty 2019). The blue line represents the TGA curve for, wherein the mass loss between $325^{\circ} \mathrm{C}-375^{\circ} \mathrm{C}$, is due to the sugarcane bagasse (SB) in the blend, and as a result, the slope of the curve becomes comparatively flatter. However, beyond $375^{\circ} \mathrm{C}$, the mass loss occurs due to the TW component in the blend. Hence, a continuous decreasing trend is noticed in the blend as compared to SB, and TW. Based on the TGA results, the co-pyrolysis of SB and TW is conducted within $\left(400-600^{\circ} \mathrm{C}\right)$ at $10^{\circ} \mathrm{C} / \mathrm{min}$, and in an inert vicinity of nitrogen.

\subsection{Experimentation on co-pyrolysis of SB, and TW}

In the first set of experiments, the thermal pyrolysis of SB was executed from 400 to $600^{\circ} \mathrm{C}$ at $10^{\circ} \mathrm{C} / \mathrm{min}$ and in an inert $\mathrm{N}_{2}$ atmosphere to establish the maximum temperature at maximum bio-oil yield. The effect of temperature on the yield of pyrolysis products and reaction time was studied and depicted in Fig. 3a. The results manifested an increase in bio-oil yield from $33.15 \mathrm{wt} . \%$ at $400^{\circ} \mathrm{C}$ to $43.02 \mathrm{wt} \%$ at 
$500^{\circ} \mathrm{C}$, after which the bio-oil yield decreased to $40.17 \mathrm{wt} . \%$ at $600^{\circ} \mathrm{C}$. The biochar yield continually reduced from $44.58 \mathrm{wt} . \%$ at $400^{\circ} \mathrm{C}$ to $27.31 \mathrm{wt} . \%$ at $600^{\circ} \mathrm{C}$, and the non-condensable non-condensables constantly increased from $27.27 \mathrm{wt} . \%$ at $400^{\circ} \mathrm{C}$ to $35.52 \mathrm{wt} . \%$ at $600^{\circ} \mathrm{C}$. The reaction time decreased from $60 \mathrm{~min}$ at $400^{\circ} \mathrm{C}$ to $27 \mathrm{~min}$ at $600^{\circ} \mathrm{C}$ indicating more release of volatile at a higher temperature. Some studies in literature reported maximum temperature for SB pyrolysis at $500^{\circ} \mathrm{C}$ for maximum bio-oil production (Mantilla et al. 2014; Varma \& Mondal, 2017).

Fig. 3(b) demonstrates the effect of temperature on yield of products, and reaction time during copyrolysis of SB: TW at 1:1 blending ratio. From Fig. 3b, it can be perceived that with excel in co-pyrolysis temperatures, the yield of the liquid product, and non-condensable increased, whereas, the bio-char yield decreased. However, the maximum bio-oil yield of $52.61 \mathrm{wt} . \%$ at $550^{\circ} \mathrm{C}$, decreased to $48.31 \mathrm{wt} . \%$ at $600^{\circ} \mathrm{C}$. On contrary, the yield of bio-char constantly decreased from $34.58 \mathrm{wt} . \%$ at $400{ }^{\circ} \mathrm{C}$ to $21.60 \mathrm{wt} . \%$ at $600^{\circ} \mathrm{C}$. The yield of non-condensables decreased from $27 \mathrm{wt} . \%$ at $400^{\circ} \mathrm{C}$ to $21.37 \mathrm{wt} . \%$ at $550^{\circ} \mathrm{C}$, and thereafter again increased to $30.09 \mathrm{wt} . \%$ at $600^{\circ} \mathrm{C}$. Whilst, the increase in the non-condensable is attributable to the decrease in the yield of co-pyrolysis liquid product. The

However, the increase in bio-oil yield is mostly due to radical interaction occurring between SB and TW which leads to a synergistic effect. Several studies are reporting in the literature that established a maximum temperature as $550^{\circ} \mathrm{C}$ for co-pyrolysis(Chen et al. 2016; Izzatie et al. 2016; Sanahuja-Parejo et al. 2019; Somasundaram and k 2019). In the utmost part of our study, by considering $550^{\circ} \mathrm{C}$ as the maximum temperature, the co-pyrolysis was conducted at various blending ratios of 1:0, 1:1. 1:2, 1:3, 3:1 and $0: 1$ at $10^{\circ} \mathrm{C} / \mathrm{min}$.

Fig. 4 portrays the effect of the blending ratio $(1: 0,1: 1,1: 3,3: 1$, and $0: 1)$ on the yield of products at $550^{\circ} \mathrm{C}$ and $10^{\circ} \mathrm{C} / \mathrm{min}$. The outcome revealed an maximum bio-oil yield of $66.75 \mathrm{wt} . \%$ at $1: 3$ (SB: TW) blending ratio. However, biochar and non-condensables showed a gradually decreasing trend. The biochar yield reduced from $27.70 \mathrm{wt}$ \% for 1:0 blend to $20.81 \mathrm{wt} \%$ for 1:3 blend, however, the least bio-char yield was found for 0:1 blend of SB: TW. The yield of non-condensable got curtailed from $31.54 \mathrm{wt} . \%$ for 1:0 blend to 12.44 wt.\% for $1: 3$ blend. However, the reaction time increased with an excel in the blending ratio of TW. The reaction time is considered as the time elapsed between the first drop of bio-oil to the last drop of bio-oil. The results revealed that, as TW in the blend increased, the bio-oil yield also increased, the reason could be due to the synergistic effect coming into play owing to high aromatic content in polystyrene. (Abnisa et al. 2013b) investigated the co-pyrolysis of palm shell and polystyrene, wherein they established a synergistic effect between the precursors to be the sole reason for excel in yield of biooil. Furthermore, the synergistic effect could be due to hydrogen transfer from polystyrene to biomass increasing yield of co-pyrolysis liquid product (Nguyen 2019).

\subsection{Fuel properties of the liquid product}


The outcome of the analysis executed for fuel properties of SB bio-oil and SB: TW liquid product at (SB: TW) 1:3 blending ratio is compared with gasoline and diesel and manifested in Table 2. The physical and fuel properties include appearance, $\mathrm{pH}$, specific gravity, water content, flash point, pour point, conradsons carbon residue, kinematic viscosity, and higher heating value. The co-pyrolysis liquid product showed two phases, of which the top organic phase was separated after centrifugation at $1200 \mathrm{rpm}$, and subsequent decantation of the organic phase, and further sent for characterization. The results displayed the improve properties of SB: TW co-pyrolysis liquid product as compared to SB thermal pyrolysis bio-oil. The SB thermal pyrolysis bio-oil color was found to be dark brown, however, the co-pyrolysis liquid product was found to be light brown in appearance. The $\mathrm{pH}$ of SB bio-oil was found to be 2.17, while, it got improved for co-pyrolysis liquid product manifesting a value of 5.10. The less $\mathrm{pH}$ value leads to corrosion of the spare parts of the internal combustion engine and is primarily attributed to acidic components present in a liquid product, and can be neutralized using process intensification techniques (Park 2017). The specific gravity of the co-pyrolysis liquid product got curtailed to 0.97 for co-pyrolysis liquid product as compared to 1.10 for SB bio-oil. The specific gravity of fuel influences spray timings and spray patterns during fuel injection in an engine Dutta, Sarkar, and Mukherjee (2014). The water content reduced from $22.56 \mathrm{wt}$ \% for SB bio-oil to $2.10 \mathrm{wt}$ \% for co-pyrolysis liquid product. However, high water content leads to the low energy density of liquid product thereby renders it unsuitable for application as a fuel Dewangan, Pradhan, and Singh (2016b). Moreover, the higher water content in the liquid product of about $30-45 \mathrm{wt} . \%$ leads to phase separation. The flashpoint got reduced from $62^{\circ} \mathrm{C}$ for SB thermal bio-oil to $35^{\circ} \mathrm{C}$ for $\mathrm{SB}$ : TW co-pyrolysis liquid product. The higher the flashpoint, the better the fuel, since it adds to the storage value of the fuel at room temperatures (Alma 2010). The pour point got curtailed from -11 for SB bio-oil to -20 for SB: TW co-pyrolysis liquid product. However, the reduction in pour point in the case of copyrolysis liquid indicates its better flowability. The conradson carbon residue was reduced from $5.86 \mathrm{wt} . \%$ for SB bio-oil to $0.95(\mathrm{w} / \mathrm{w})$ in the case of co-pyrolysis liquid product. However, the increased value of carbon residue could be ascribed to the higher carbon content in the liquid product, which leads to burning problems thereby leading to abrasive wear of the engine parts Dutta, Sarkar, and Mukherjee (2014). The kinematic viscosity also got reduced in the case of co-pyrolysis to $3.70 \mathrm{cSt}$ as compared with SB bio-oil (14.20 cSt). The higher kinematic viscosity reduces the atomization of the fuel in the engine and surges fuel spray penetration. (Ravikumar et al. 2017). The calorific value increased from $32 \mathrm{MJ} / \mathrm{Kg}$ for SB bio-oil to $41.05 \mathrm{MJ} / \mathrm{kg}$ for SB: TW co-pyrolysis liquid product. The calorific value of the copyrolysis liquid product was found a little higher than the range of values reported in the literature by (Suriapparao et al. 2018). The elemental analysis results manifested an improved ' $C$ ' content $(82.15 \%)$ in the case of co-pyrolysis liquid product as compared to SB thermal pyrolysis bio-oil (65.64 \%). However, the ' $O$ ' content reduced in case of co-pyrolysis liquid product (7.38 \%) when compared with SB thermal pyrolysis bio-oil (26.67\%). The nitrogen present was found to be higher in the co-pyrolysis liquid product, and there is no sulfur found in the co-pyrolysis liquid product as compared to SB thermal pyrolysis bio-oil. The presence of no sulfur decreases $\mathrm{SO}_{\mathrm{x}}$ emission, whereas the presence of fewer nitrogen compounds may probably lead to some $\mathrm{NO}_{x}$ emissions during combustion. The $\mathrm{H} / \mathrm{C}$ ratio is found higher for copyrolysis liquid product (1.35\%) as compared to SB (1.27\%) bio-oil. Whereas, the O/C ratio for SB: TW bio-oil $(0.06 \%)$ was found lower as compared to SB bio-oil $(0.30 \%)$. However, the high calorific value for 
co-pyrolysis liquid product is due to less water present, and a high $\mathrm{H} / \mathrm{C}$ ratio Dewangan, Pradhan, and Singh (2016c). Moreover, the increase in HHV for the liquid product, during co-pyrolysis of lignocellulosic biomass and waste plastic is ascribed to a positive synergistic effect (Zhang et al. 2016). However, the improved properties in the case of SB: TW co-pyrolysis liquid product is attributed to synergistic effect coming into play due to interaction between olefins derived from plastics with the lignocellulosic components of biomass Özsin and Pütün (2018).

Table. 2 Comparison of bio-oil properties obtained from SB, co-pyrolysis of (SB:TW) with diesel, and gasoline 


\begin{tabular}{|c|c|c|c|c|c|}
\hline Properties & $\begin{array}{l}\text { SB bio- } \\
\text { oil }\end{array}$ & $\begin{array}{l}\text { SB: TW } \\
\text { bio-oil }\end{array}$ & $\begin{array}{l}\text { Commercial } \\
\text { Diesel }\end{array}$ & Gasoline & ASTM \\
\hline Appearance & $\begin{array}{l}\text { Dark } \\
\text { Brown }\end{array}$ & $\begin{array}{l}\text { Light } \\
\text { Brown }\end{array}$ & Yellow & Green & - \\
\hline $\mathrm{pH}$ & 2.17 & 5.1 & $5.5-8.0$ & - & - \\
\hline Specific gravity (g/ml) & 1.10 & 0.97 & 0.84 & $\begin{array}{l}0.72- \\
0.78\end{array}$ & $\begin{array}{l}\text { ASTM } \\
\text { D4052 }\end{array}$ \\
\hline Water content (wt.\%) & 22.56 & 2.10 & $0-0.02$ & - & $\begin{array}{l}\text { ASTM D95- } \\
83\end{array}$ \\
\hline Flash point $\left({ }^{\circ} \mathrm{C}\right)$ & 62 & 32 & $60-80$ & 43 & ASTM D92 \\
\hline Pour point $\left({ }^{\circ} \mathrm{C}\right)$ & -11 & -20 & -16 & -40 & ASTM D97 \\
\hline $\begin{array}{l}\text { Conradson carbon residue } \\
\text { (wt.\%) }\end{array}$ & 5.86 & 1.2 & $<=0.15$ & - & ASTM D189 \\
\hline $\begin{array}{l}\text { Kinematic viscosity at } 40^{\circ} \mathrm{C} \\
\text { (cSt) }\end{array}$ & 14.20 & 3.70 & $2-4.5$ & - & $\begin{array}{l}\text { ASTM D } \\
445\end{array}$ \\
\hline Calorific value (MJ/kg) & 32.00 & 41.05 & $42-46$ & $44-46$ & $\begin{array}{l}\text { ASTM D } \\
240\end{array}$ \\
\hline Ultimate Analysis (wt. \%) & & & & & $\begin{array}{l}\text { ASTM } \\
\text { D5291-96 }\end{array}$ \\
\hline Carbon (wt.\%) & 65.64 & 82.15 & $84-87$ & 84.2 & - \\
\hline Hydrogen (wt.\%) & 6.97 & 10.21 & $11-15$ & 15.8 & - \\
\hline Nitrogen (wt.\%) & 0.69 & 0.26 & $0.01-0.3$ & - & - \\
\hline Sulfur (wt.\%) & 0.03 & - & - & - & - \\
\hline Oxygen $^{*}$ (wt.\%) & 26.67 & 7.38 & - & - & - \\
\hline $\mathrm{H} / \mathrm{C}$ & 1.27 & 1.49 & 1.87 & 2.3 & - \\
\hline O/C & 0.30 & 0.06 & 0.0052 & - & - \\
\hline
\end{tabular}

* By difference

The FT-IR spectra of SB and SB: TW co-pyrolysis liquid product is portrayed in Fig. 5, wherein the peaks are manifested in transmittance mode. The SB bio-oil revealed the presence of polymeric O-H group TW $\left(3464 \mathrm{~cm}^{-1}\right)$, nitriles $\left(2357 \mathrm{~cm}^{-1}\right)$, carboxylic acids, esters and ketones $\left(1728 \mathrm{~cm}^{-1}\right)$, alkenes $\left(1595 \mathrm{~cm}^{-}\right.$ $\left.{ }^{1}\right)$, alkanes $\left(1402 \mathrm{~cm}^{-1}\right)$, alcohols, phenols and esters $\left(1281\right.$ and $\left.1057 \mathrm{~cm}^{-1}\right)$ and aromatic compound $\left(681 \mathrm{~cm}^{-1}\right)$. Whereas, in co-pyrolysis liquid product, most of the functional group TW like polymeric $0-\mathrm{H}$, 
alcohols, phenols, and esters vanquished which were present in the SB bio-oil, and most of the aromatic compounds exist in the form of peaks at 3037, 1504, 905, and $692 \mathrm{~cm}^{-1}$. However, excel in aromatic compounds is attributed to the incorporation of TW which has a high $\mathrm{H} / \mathrm{C}$ ratio. The increase in aromatics for the co-pyrolysis liquid product could be due to the conversion of phenolics by hydrogenation. However, the reduction in phenolic compounds is reported in literatures during copyrolysis of grape seeds and polystyrene (Sanahuja-Parejo et al. 2019). Whilst, the effect of synergy is explained by many researchers in their respective work, showed an excel in quality of the co-pyrolysis liquid product (Shadangi and Mohanty 2015b; Ozsin 2018; Reshad, Tiwari, and Goud 2019; Akancha, Kumari, and Singh 2019; Hassan, Hameed, and Lim 2020).

The outcome of GC-MS analysis is manifested in Table. 3 which includes compound name, chemical formula, and area (\%) for SB and SB: TW co-pyrolysis liquid product. The results of SB bio-oil manifested the presence of phenols, aldehydes, ketones, acids, esters, and some amount of amines. Whereas, the copyrolysis liquid product found a tremendous decrease in phenolic compounds from $27.42 \%$ for SB bio-oil to $1.76 \%$ for co-pyrolysis liquid product. Also, the presence of aldehydes and ketones also displays a similar decreasing trend from $26.71 \%$ for SB bio-oil to $1.16 \%$ for co-pyrolysis liquid product. Furthermore, ester and acidic compounds also show a reducing trend from $12.06 \%$ for SB bio-oil to $1.38 \%$ for copyrolysis liquid product. However, the aromatic compounds showed a gradually increasing trend from $4.95 \%$ to $12.45 \%$ for SB bio-oil to SB: TW bio-oil, respectively. From the comparative study, a reduction in phenolic, acidic compounds, and an increase in aromatic compounds along with some straight-chain hydrocarbons was observed. The reduction in phenolic compounds is also established during the copyrolysis studies of calotropis procera stem and polystyrene (Radhaboy and Pugazhvadivu 2020).

Table. 3 Chemical compounds present in bio-oil from SB thermal pyrolysis and SB: TW co-pyrolysis liquid 


\begin{tabular}{|c|c|c|c|}
\hline Compound Name & $\begin{array}{l}\text { Chemical } \\
\text { Formula }\end{array}$ & $\begin{array}{l}\text { Area \% of SB bio- } \\
\text { oil }\end{array}$ & $\begin{array}{l}\text { Area \% of } \\
\text { SB:TW } \\
\text { bio-oil }\end{array}$ \\
\hline Bicyclo[4.2.0]octa-1,3,5-triene & $\mathrm{C}_{8} \mathrm{H}_{8}$ & - & 4.20 \\
\hline Benzene, 1-ethyl-4-methoxy- & $\mathrm{C}_{9} \mathrm{H}_{12} \mathrm{O}$ & 1.10 & - \\
\hline Benzene, 1,1'-(1,3-propanediyl)bis & $\mathrm{C}_{15} \mathrm{H}_{16}$ & - & 2.10 \\
\hline Benzene, 1,1'-(3-methyl-1-propen & $\mathrm{C}_{16} \mathrm{H}_{16}$ & - & 1.57 \\
\hline 1,2-Benzenediol, 3-methoxy & $\mathrm{C}_{7} \mathrm{H}_{8} \mathrm{O}_{3}$ & 1.19 & - \\
\hline Benzene, 1,1'-(3-methyl-1-propene & $\mathrm{C}_{16} \mathrm{H}_{16}$ & - & 0.81 \\
\hline Benzene, 1,1'-(1-butene-1,4-diyl & $\mathrm{C}_{16} \mathrm{H}_{16}$ & - & 0.75 \\
\hline 1,2-Benzenediol, 3-methyl- & $\mathrm{C}_{7} \mathrm{H}_{8} \mathrm{O}_{2}$ & 0.96 & - \\
\hline $\begin{array}{l}\text { Benzene, 1,1'-(2-methyl-1- } \\
\text { propenylidene }\end{array}$ & $\mathrm{C}_{16} \mathrm{H}_{16}$ & - & 0.73 \\
\hline Benzene, 1,1'-(1-methyl-1,3-propene & $\mathrm{C}_{18} \mathrm{H}_{20}$ & - & 1.10 \\
\hline Hydroquinone & $\mathrm{C}_{6} \mathrm{H}_{6} \mathrm{O}_{2}$ & 0.46 & - \\
\hline Benzene, (1-methylethyl)- & $\mathrm{C}_{9} \mathrm{H}_{12}$ & - & 0.57 \\
\hline Galactitol & $\mathrm{C}_{6} \mathrm{H}_{14} \mathrm{O}_{6}$ & 1.12 & - \\
\hline Benzene, 1,4,9-decatrienyl- & $\mathrm{C}_{16} \mathrm{H}_{20}$ & - & 0.71 \\
\hline Benzene, 1-ethenyl-3-methyl- & $\mathrm{C}_{9} \mathrm{H}_{10}$ & - & 0.43 \\
\hline Benzene, 3-butenyl- & $\mathrm{C}_{10} \mathrm{H}_{12}$ & - & 0.08 \\
\hline Benzene, 1-methoxy-4-methyl- & $\mathrm{C}_{8} \mathrm{H}_{10} \mathrm{O}$ & - & 0.01 \\
\hline Benzene, (1-methylpropyl)- & $\mathrm{C}_{10} \mathrm{H}_{14}$ & - & 0.05 \\
\hline Benzene, 1,2,4-trimethyl- & $\mathrm{C}_{9} \mathrm{H}_{12}$ & - & 0.04 \\
\hline Phenol & $\mathrm{C}_{6} \mathrm{H}_{5} \mathrm{OH}$ & 4.22 & 0.24 \\
\hline Phenol, 2,4-dimethyl- & $\mathrm{C}_{8} \mathrm{H}_{10} \mathrm{O}$ & 0.81 & - \\
\hline Phenol, 2,3-dimethyl- & $\mathrm{C}_{8} \mathrm{H}_{10} \mathrm{O}$ & 0.53 & - \\
\hline Phenol, 2-methyl- & $\mathrm{C}_{7} \mathrm{H}_{8} \mathrm{O}$ & 1.10 & - \\
\hline
\end{tabular}




\begin{tabular}{|c|c|c|c|}
\hline Phenol, 4-ethyl- & $\mathrm{C}_{8} \mathrm{H}_{10} \mathrm{O}$ & 4.63 & 0.59 \\
\hline Phenol, 2-methoxy- & $\mathrm{C}_{7} \mathrm{H}_{8} \mathrm{O}_{2}$ & 2.26 & - \\
\hline Phenol, 4-ethyl-2-methoxy- & $\mathrm{C}_{9} \mathrm{H}_{12} \mathrm{O}_{2}$ & 1.58 & - \\
\hline Phenol, 3,4-dimethyl- & $\mathrm{C}_{8} \mathrm{H}_{10} \mathrm{O}$ & - & 0.12 \\
\hline Phenol, 2,6-dimethoxy- & $\mathrm{C}_{8} \mathrm{H}_{10} \mathrm{O}_{3}$ & - & 0.22 \\
\hline 1,2,4-Trimethoxybenzene & $\mathrm{C}_{9} \mathrm{H}_{12} \mathrm{O}_{3}$ & - & 0.32 \\
\hline Sulfurous acid, nonyl 2-propyl ester & $\mathrm{C}_{12} \mathrm{H}_{26} \mathrm{O}_{3} \mathrm{~S}$ & 0.54 & - \\
\hline 2-Furancarboxaldehyde, 5-methyl- & $\mathrm{C}_{6} \mathrm{H}_{6} \mathrm{O}_{2}$ & 0.99 & 0.15 \\
\hline Vanillin & $\mathrm{C}_{8} \mathrm{H}_{8} \mathrm{O}_{3}$ & 0.72 & - \\
\hline Furfural & $\mathrm{C}_{5} \mathrm{H}_{4} \mathrm{O}_{2}$ & 10.94 & - \\
\hline a-Methyl styrene & $\mathrm{C}_{9} \mathrm{H}_{10}$ & - & 3.18 \\
\hline p-Cresol & $\mathrm{C}_{7} \mathrm{H}_{8} \mathrm{O}$ & 3.83 & - \\
\hline Hydracrylic acid, monoanhydride & & 0.99 & - \\
\hline Creosol & $\mathrm{C}_{8} \mathrm{H}_{10} \mathrm{O}_{2}$ & 1.09 & 0.21 \\
\hline 1-Penten-3-ol & $\mathrm{C}_{5} \mathrm{H}_{10} \mathrm{O}$ & 1.08 & - \\
\hline 2-Methoxy-4-vinylphenol & $\mathrm{C}_{9} \mathrm{H}_{10} \mathrm{O}_{2}$ & - & 0.38 \\
\hline Octadecane & $\mathrm{C}_{18} \mathrm{H}_{38}$ & - & 1.12 \\
\hline 2-Cyclopenten-1-one, 2-methyl- & $\mathrm{C}_{6} \mathrm{H}_{8} \mathrm{O}$ & 1.42 & - \\
\hline 2(5H)-Furanone & $\mathrm{C}_{4} \mathrm{H}_{4} \mathrm{O}_{2}$ & 1.31 & - \\
\hline 4-Isopropyl-1,3-cyclohexanedione & $\mathrm{C}_{9} \mathrm{H}_{14} \mathrm{O}_{2}$ & - & 0.31 \\
\hline 1,2-Cyclopentanedione & $\mathrm{C}_{5} \mathrm{H}_{6} \mathrm{O}_{2}$ & 1.05 & - \\
\hline 2-Cyclopenten-1-one, 3-ethyl-2-h.. & $\mathrm{C}_{7} \mathrm{H}_{10} \mathrm{O}$ & 0.96 & - \\
\hline 2-Cyclopenten-1-one, 2-hydroxy-3 & $\mathrm{C}_{6} \mathrm{H}_{8} \mathrm{O}_{2}$ & 4.27 & - \\
\hline$\beta$-D-Glucopyranose, 1,6-anhy & $\mathrm{C}_{6} \mathrm{H}_{10} \mathrm{O}_{5}$ & 7.96 & - \\
\hline 1-Tridecene & $\mathrm{C}_{13} \mathrm{H}_{26}$ & - & 0.48 \\
\hline 1-Nonadecene & & - & 0.47 \\
\hline
\end{tabular}




\begin{tabular}{|llll|}
\hline \multicolumn{3}{|c|}{$\mathrm{C}_{19} \mathrm{H}_{38}$} & \\
2-Tetradecene & $\mathrm{C}_{14} \mathrm{H}_{28}$ & - & 0.43 \\
\hline 1-Pentadecene & $\mathrm{C}_{15} \mathrm{H}_{30}$ & - & 0.66 \\
\hline 3,4-Altrosan & $\mathrm{C}_{6} \mathrm{H}_{10} \mathrm{O}_{5}$ & 3.84 & - \\
\hline 1-Propene, 3-(2-cyclopentenyl)-2 & $\mathrm{C}_{21} \mathrm{H}_{22}$ & - & 1.95 \\
\hline 1,4:3,6-Dianhydro-a-d-glucopyranose & $\mathrm{C}_{6} \mathrm{H}_{8} \mathrm{O}_{4}$ & 5.48 & - \\
\hline Anthracene, 9,10-dihydro-9,10-di & $\mathrm{C}_{16} \mathrm{H}_{16} \mathrm{O}_{2}$ & - & 1.38 \\
\hline Naphthalene, 1,2,3,4-tetrahydro- & $\mathrm{C}_{10} \mathrm{H}_{12}$ & - & 2.64 \\
\hline Maltol & $\mathrm{C}_{6} \mathrm{H}_{6} \mathrm{O}_{3}$ & 0.73 & - \\
\hline Naphthalene, 2-phenyl- & $\mathrm{C}_{16} \mathrm{H}_{12}$ & - & 0.77 \\
\hline
\end{tabular}

The results of ${ }^{1} \mathrm{H}$ NMR analysis of the bio-oil gotten from pyrolysis of thermal SB pyrolysis, and SB: TW co-pyrolysis liquid obtained at 1:3 ratio is displayed in Table 4, and Fig. 6 (a) \& (b) that demonstrated the spectrum of SB and SB: TW co-pyrolysis liquid product. The outcome of the ${ }^{1} \mathrm{H}-\mathrm{NMR}$ analysis exhibited that SB bio-oil constituted mainly protons of alkynes and a-substituted monoaromatics such as $\mathrm{CH}, \mathrm{CH}_{2}$, and $\mathrm{CH}_{3 \mathrm{a}}$. Whereas, the co-pyrolysis liquid product showed the presence of many aromatic protons which is due to the aromatic presence of TW. The comparative study results showed that aromatic protons increased from $0.06 \%$ for SB bio-oil to $11.48 \%$ for co-pyrolysis liquid product. However, the increase in aromatic peaks for co-pyrolysis liquid product is ascribed to a synergistic effect between the feedstocks (SB and TW). Many researchers have reported the transition towards aromaticity with the incorporation of polymers with biomass in the pyrolysis (Paradela et al. 2009; Özsin and Pütün 2018).

Table. $4{ }^{1} \mathrm{H}-\mathrm{NMR}$ result of SB and co-pyrolysis (SB: TW) bio-oil 


\begin{tabular}{|llll|}
\hline Chemical Shift & $\begin{array}{l}\mathrm{SB} \\
\text { bio-oil }\end{array}$ & $\begin{array}{l}\text { SB: TW } \\
\text { bio-oil }\end{array}$ & Assignments \\
\hline $0.5-1.0$ & - & - & $\mathrm{CH}_{3 \gamma}$ and Naphthenic $-\mathrm{CH}$ and $\mathrm{CH}_{2}$ \\
\hline $1.0-1.6$ & - & 1.13 & $\mathrm{~B}^{-} \mathrm{CH}_{3}, \mathrm{CH}_{2}$, and $\mathrm{CH}_{\gamma}$ or from an aromatic ring \\
\hline $1.6-2.0$ & 0.38 & - & $\mathrm{CH}_{2}, \mathrm{CH}_{\beta}$ to an aromatic ring \\
\hline $2.0-3.3$ & 1.00 & 2.53 & $\mathrm{CH}, \mathrm{CH}_{2}, \mathrm{CH}_{3 \mathrm{a}}$ to an aromatic ring \\
\hline $3.3-4.5$ & 0.79 & - & $\mathrm{CH}_{2}$ bridge (Diphenylmethane) \\
\hline $5.0-6.5$ & 0.42 & 1.49 & $\mathrm{Phenolic}^{-} \mathrm{OH} /$ Olefinic Proton \\
\hline $6.5-9.0$ & 0.06 & 11.48 & Aromatic rings \\
\hline
\end{tabular}

\subsection{Characterization of biochars}

The biochar obtained from SB and SB: TW co-pyrolysis under maximum condition is subjected to characterizations like ultimate analysis, $\mathrm{pH}$, and higher heating value are presented in the Table. 5 . The ultimate composition results showed that the carbon content for SB and co-pyrolysis bio-char is $65.37 \%$, and $80.70 \%$; hydrogen content of $3.90 \%$, and $3.58 \%$; nitrogen content of $0.93 \%$, and $0.31 \%$; sulfur content of $0.04 \%$, and $0.01 \%$, and finally oxygen content of $29.76 \%$, and $15.40 \%$ respectively. The pH of SB biochar, SB: TW biochar was found to be 8.2 and 9.1 respectively. The alkalinity of the bio-char makes it suitable for soil amendment by decreasing its acidity. The higher heating value of SB and SB: TW bio-char is found to $24.30 \mathrm{MJ} / \mathrm{Kg}$ and $31.42 \mathrm{MJ} / \mathrm{kg}$ respectively. The low higher heating value of SB as compared to SB: TW biochar is due to less ' $\mathrm{C}$ ' content in SB in comparison to SB: TW biochar. The high calorific value and fixed carbon content in co-pyrolysis bio-char facilitate its use as a solid fuel. The nearby higher heating value of the obtained SB: TW co-pyrolysis biochar was reported in the literature by (Brebu et al. 2010).

Table. 5 Properties of SB and SB: TW co-pyrolysis bio-char 


\begin{tabular}{|lll|}
\hline Properties & SB bio-char & SB: TW bio-char \\
\hline Ultimate composition (wt. \%) \\
\hline Carbon & 65.37 & 80.7 \\
\hline Hydrogen & 3.90 & 3.58 \\
\hline Nitrogen & 0.93 & 0.31 \\
\hline Sulfur & 0.04 & 0.01 \\
\hline Oxygen $^{*}$ & 29.76 & 15.40 \\
\hline pH & 8.2 & 9.1 \\
\hline HHV $(\mathrm{MJ} / \mathrm{kg})$ & 24.30 & 31.42 \\
\hline
\end{tabular}

* By difference

The SEM micrographs of SB and SB:TW biochar is illustrated in Fig. 7 (a) \& (b), respectively. The results of the surface morphology revealed that the number of pores reduces and pore size enhances for the SB:TW bio-char as compared to SB biochar. The reduction in pores and increase in the size of the pores may be due to the melting of TW during co-pyrolysis which enters into the bulk of SB and enlarged the pores thereby reduced the number of pores. However, the increase in pores size on the surface of copyrolysis biochar is probably due to more volatilization during co-pyrolysis of SB:TW than during the thermal pyrolysis of SB. Moreover, the surface morphology of SB: TW char was found rough as compared to the SB bio-char surface, wherein the roughness in the co-pyrolysis char is attributed to the incorporation of TW which is aromatic. The SEM analysis results of SB biochar obtained from current study is in accordance with the results reported in literature (Biswas et al. 2020). It can be concluded from the SEM analysis that pore size of both the chars is found suitable for using in adsorption studies. Nevertheless, due to enlarged pore size in co-pyrolysis char, it would be suggested for better adsorption as compared to SB biochar.

The FT-IR spectrum of SB and SB:TW co-pyrolysis bio-char is depicted in Fig. 8. The FT-IR spectra for SB bio-char showed a peak at $2347 \mathrm{~cm}^{-1}$, signifies the $\mathrm{C}-\mathrm{H}$ vibration occur owing to the occurrence of alkanes. Peaks at 1698 and $1421 \mathrm{~cm}^{-1}$ corresponds to $\mathrm{CH}_{2}$ group which arose owing to $\mathrm{C}-\mathrm{O}$ bond stretch in carboxylic acid and esters. The peak at $1581 \mathrm{~cm}^{-1}$ is owing to $\mathrm{C}-\mathrm{C}$ and $\mathrm{C}-\mathrm{O}$ stretching of aromatic rings. and the utmost peak at $655 \mathrm{~cm}^{-1}$ arose due to $\mathrm{C}-\mathrm{Cl}$ stretch. While, the SB:TW bio-char showed the various peaks at $2358 \mathrm{~cm}^{-1}$ owing to $\mathrm{C}-\mathrm{H}$ vibration, at $1592 \mathrm{~cm}^{-1}$ due to $\mathrm{C}-\mathrm{C}$ and $\mathrm{C}-\mathrm{O}$ stretch in aromatic rings, at $1442 \mathrm{~cm}^{-1}$ due to aliphatic $\mathrm{CH}_{2}$ stretching. Peaks at $867 \mathrm{~cm}^{-1}$ is due to presence of styrene, and 
the peaks below $800 \mathrm{~cm}^{-1}$ i.e., $751 \mathrm{~cm}^{-1}, 698 \mathrm{~cm}^{-1}$ is owing to stretching of higher hydrocarbons, and $\mathrm{C}-\mathrm{H}$ groups respectively. For sugarcane bagasse biochar we reported similar peaks in the literature by (Ding et al. 2014). Since FT-IR analysis of sugarcane bagasse, and thermocol waste co-pyrolysis char have not been reported in literatures, concordant findings was reported in literatures upon co-pyrolysis of sawdust, and polystyrene by (Stančin et al. 2021).

\section{Conclusion}

The co-pyrolysis of SB and TW was executed using a semi-batch reactor to establish the maximum temperature and blending ratio for maximum bio-oil yield and thus characterize the maximum product. The co-pyrolysis experiment results established an maximum bio-oil yield of $66.75 \mathrm{wt} . \%$ at an maximum temperature of $550^{\circ} \mathrm{C}$, at a $1: 3$ blending ratio of SB: TW. The co-pyrolysis liquid product manifested a calorific value of $41.05 \mathrm{MJ} / \mathrm{kg}$, which was in the near range of ASTM values of diesel. The GC-MS and FTIR results showed a significant increase in aromatic compounds and a substantial reduction in oxygenated compounds in the co-pyrolysis SB: TW bio-oil in comparison to SB thermal pyrolysis bio-oil. The FT-IR analysis of co-pyrolysis bio-char confirms the presence of more aromatic compounds and contained an HHV of $30.66 \mathrm{MJ} / \mathrm{kg}$. The SEM analysis results revealed that the pore size enhances for the SB: TW bio-char as compared to SB bio-char. It is established that the co-pyrolysis bio-char for its porosity and high calorific value which promotes its application as an adsorbent as well as a fuel. The radical characterizations of the bio-oil revealed that it can be considered as a potential drop-in fuel in transportation as well as a source of value-added chemicals.

\section{Abbreviations}

SB - Sugarcane bagasse

TW - Thermocol waste

PE- Polyethylene

PP - Polypropylene

ASTM - American standard for testing and materials

HHV - Higher heating value

TGA - Thermogravimetric analysis

FT-IR - Fourier transform infrared spectroscopy

GC-MS - Gass chromatography-mass spectrometry

${ }^{1} \mathrm{H}$ - NMR- Proton- Nuclear magnetic resonance 
SEM - Scanning electron microscope

\section{Declarations}

\section{Competing interests}

The authors declare that there are no competing interests involved in the manuscript.

\section{References}

Abnisa, Faisal et al. (2013) "Co-Pyrolysis of Palm Shell and Polystyrene Waste Mixtures to Synthesis Liquid Fuel." Fuel 108: 311-18. https://doi.org/10.1016/j.fuel.2013.02.013

Abnisa, Faisal, and Wan Mohd Ashri Wan Daud. ( 2014) "A Review on Co-Pyrolysis of Biomass: An Optional Technique to Obtain a High-Grade Pyrolysis Oil." Energy Conversion and Management 87: 7185. https://doi.org/10.1016/j.enconman.2014.07.007

Akancha, Namrata Kumari, and R. K. Singh. (2019) "Co-Pyrolysis of Waste Polypropylene and Rice Bran Wax- Production of Biofuel and Its Characterization." Journal of the Energy Institute 92(4): 933-46. https://doi.org/10.1016/j.joei.2018.07.011

Alma, M Hakkı. (2010) "Journal of Analytical and Applied Pyrolysis Pyrolysis of Laurel ( Laurus Nobilis L .) Extraction Residues in a Fixed-Bed Reactor: Characterization of Bio-Oil and Bio-Char Murat Ertas." 88: 22-29. https://doi.org/10.1016/j.jaap.2010.02.006

Asadullah, M. et al. (2007) "Production of Bio-Oil from Fixed Bed Pyrolysis of Bagasse." Fuel 86(16): 2514-20. https://doi.org/10.1016/j.fuel.2007.02.007

Bhattacharya, Priyanka et al. (2009) "Wood/Plastic Copyrolysis in an Auger Reactor: Chemical and Physical Analysis of the Products." Fuel 88 (7): 1251-60. https://doi.org/10.1016/j.fuel.2009.01.009

Biswas, Subrata et al. (2020) "Batch and Continuous Closed Circuit Semi-Fluidized Bed Operation: Removal of MB Dye Using Sugarcane Bagasse Biochar and Alginate Composite Adsorbents." Journal of Environmental Chemical Engineering 8(1): https://doi.org/10.1016/j.jece.2019.103637

Brebu, Mihai, Suat Ucar, Cornelia Vasile, and Jale Yanik. (2010) "Co-Pyrolysis of Pine Cone with Synthetic Polymers." Fuel 89(8): 1911-18. https://doi.org/10.1016/j.fuel.2010.01.029

Çepelioğullar, Özge, and Ayşe E. Pütün. (2013) "Thermal and Kinetic Behaviors of Biomass and Plastic Wastes in Co-Pyrolysis." Energy Conversion and Management 75: 263-70. https://doi.org/10.1016/j.enconman.2013.06.036

Chandel, Anuj K, S Silva, and Om V Singh. (2012) "Sugarcane Bagasse and Leaves: Foreseeable Biomass of Biofuel and Bio-Products." (November 2011): 11-20. https://doi.org/10.1002/jctb.2742 
Chen, Weimin et al. 2016. "Co-Pyrolysis of Waste Newspaper with High-Density Polyethylene: Synergistic Effect and Oil Characterization." Energy Conversion and Management 112: 41-48.

https://doi.org/10.1016/j.enconman.2016.01.005

Dewangan, Ashish, Debalaxmi Pradhan, and R. K. Singh. (2016) "Co-Pyrolysis of Sugarcane Bagasse and Low-Density Polyethylene: Influence of Plastic on Pyrolysis Product Yield." Fuel 185: 508-16.

https://doi.org/10.1016/j.fuel.2016.08.011

Ding, Wenchuan et al. (2014) "Pyrolytic Temperatures Impact Lead Sorption Mechanisms by Bagasse Biochars." Chemosphere 105: 68-74. https://doi.org/10.1016/j.chemosphere.2013.12.042

Dutta, Ratna, Ujjaini Sarkar, and Alakananda Mukherjee. (2014) "Extraction of Oil from Crotalaria Juncea Seeds in a Modified Soxhlet Apparatus: Physical and Chemical Characterization of a Prospective." 116: 794-802. https://doi.org/10.1016/j.fuel.2013.08.056

Goyal, H. B., Diptendu Seal, and R. C. Saxena. (2008) "Bio-Fuels from Thermochemical Conversion of Renewable Resources: A Review." Renewable and Sustainable Energy Reviews 12(2): 504-17. https://doi.org/10.1016/j.rser.2006.07.014

Hassan, H., B. H. Hameed, and J. K. Lim. (2020) "Co-Pyrolysis of Sugarcane Bagasse and Waste HighDensity Polyethylene: Synergistic Effect and Product Distributions." Energy 191: 116545. https://doi.org/10.1016/j.energy.2019.

Hassan, H., J. K. Lim, and B. H. Hameed. (2016) "Recent Progress on Biomass Co-Pyrolysis Conversion into High-Quality Bio-Oil." Bioresource Technology 221: 645-55.

https://doi.org/10.1016/j.biortech.2016.09.026

Islam, Mohammad Rofiqul, Momtaz Parveen, and Hiroyuki Haniu. (2010) "Properties of Sugarcane Waste-Derived Bio-Oils Obtained by Fixed-Bed Fire-Tube Heating Pyrolysis." Bioresource Technology 101(11): 4162-68. https://doi.org/10.1016/j.biortech.2009.12.137

Izzatie, N I et al. (2016) "Co-Pyrolysis of Rice Straw and Polypropylene Using Fixed-Bed Pyrolyzer." IOP Conference Series: Materials Science and Engineering 160: 012033. doi:10.1088/1757$899 X / 160 / 1 / 012033$

Lam, Su Shiung et al. (2016) "Progress in Waste Oil to Sustainable Energy, with Emphasis on Pyrolysis Techniques." Renewable and Sustainable Energy Reviews 53: 741-53.

https://doi.org/10.1016/j.rser.2015.09.005

Maia, L C Morais A A D, and M E G Guandique A H Rosa. (2017) "Pyrolysis and Combustion of Sugarcane Bagasse." Journal of Thermal Analysis and Calorimetry 129: 1813-1822 10.1007/s10973-017-6329-x

Mantilla, Sebastián Vecino, Paola Gauthier-maradei, Pedro Álvarez Gil, and Sindy Tarazona Cárdenas. (2014) “Comparative Study of Bio-Oil Production from Sugarcane Bagasse and Palm Empty Fruit Bunch: 
Yield Optimization and Bio-Oil Characterization 108: 284-294 Journal of Analytical and Applied Pyrolysis. http://dx.doi.org/10.1016/j.jaap.2014.04.003.

Mishra, Ranjeet Kumar, and Kaustubha Mohanty. (2019) "Pyrolysis of Three Waste Biomass: Effect of Biomass Bed Thickness and Distance between Successive Beds on Pyrolytic Products Yield and Properties." 141: 549-58. https://doi.org/10.1016/j.renene.2019.04.044

Naidu, Appala, Srikanta Dinda, and Bhanu Radhika. (2020) "Scientific and Engineering Aspects of Potential Applications of Post-Consumer ( Waste ) Expanded Polystyrene: A Review." Process Safety and Environmental Protection 137: 140-48. https://doi.org/10.1016/j.psep.2020.02.023.

Nanda, Sonil, Javeed Mohammad, and Sivamohan N Reddy. (2014) "Pathways of Lignocellulosic Biomass Conversion to Renewable Fuels." 4: 157-191. 10.1007/s13399-013-0097-z

Nguyen, Quynh Van et al. (2019) "Improvement of Bio-Crude Oil Properties via Co-Pyrolysis of Pine Sawdust and Waste Polystyrene Foam." Journal of Environmental Management 237; 24-29. https://doi.org/10.1016/j.jenvman.2019.02.039.

Nisar, Jan et al. (2019) "Fuel Production from Waste Polystyrene via Pyrolysis: Kinetics and Products Distribution." 88: 236-47. https://doi.org/10.1016/j.wasman.2019.03.035

Ozsin, Gamzenur. (2018) "A Comparative Study on Co-Pyrolysis of Lignocellulosic Biomass with Polyethylene Terephthalate, Polystyrene, and Polyvinyl Chloride: Synergistic Effects and Product Characteristics." 205: 1127-38. https://doi.org/10.1016/j.jclepro.2018.09.134

Özsin, Gamzenur, and Ayşe Eren Pütün. (2018) "Co-Pyrolytic Behaviors of Biomass and Polystyrene: Kinetics, Thermodynamics and Evolved Gas Analysis." Korean Journal of Chemical Engineering 35(2): 428-37. DOI: $10.1007 /$ s11814-017-0308-6

Özsin, Gamzenur, Ayşe Eren Pütün, and Ersan Pütün. (2019) “Investigating the Interactions between Lignocellulosic Biomass and Synthetic Polymers during Co-Pyrolysis by Simultaneous Thermal and Spectroscopic Methods." Biomass Conversion and Biorefinery 9(3): 593-608.

https://doi.org/10.1007/s13399-019-00390-9

Pandey, Ashok, Carlos R. Soccol, Poonam Nigam, and Vanete T. Soccol. (2000) "Biotechnological Potential of Agro-Industrial Residues. I: Sugarcane Bagasse." Bioresource Technology 74(1): 69-80. PII: S 0960 - 8524 ( 99 ) $00142-X$

Paradela, Filipe et al. (2009) "Study of the Slow Batch Pyrolysis of Mixtures of Plastics, Tyres and Forestry Biomass Wastes." Journal of Analytical and Applied Pyrolysis 85(1-2): 392-98. https://doi.org/10.1016/j.jaap.2008.09.003

Park, Lydia Kyoung-eun et al. (2017) " $\mathrm{pH}$ Neutralization of Aqueous Bio-Oil from Switchgrass Intermediate Pyrolysis Using Process Intensi Fi Cation Devices.". Energy Fuels 31: 9455-9464. 
http://dx.doi.org/10.1021/acs.energyfuels.7b00854

Pradhan, Debalaxmi, Vikranth Volli, R K Singh, and S Murgun. (2020) "Co-Pyrolysis Behavior, Engine Performance Characteristics, and Thermodynamics of Liquid Fuels from Mahua Seeds and Waste Thermocol: A Comprehensive Study." Chemical Engineering Journa/393(March): 124749. https://doi.org/10.1016/j.cej.2020.124749.

Ravikumar, C. et al. (2017) "Microwave Assisted Fast Pyrolysis of Corn Cob, Corn Stover, Saw Dust and Rice Straw: Experimental Investigation on Bio-Oil Yield and High Heating Values." Sustainable Materials and Technologies 11: 19-27. http://dx.doi.org/10.1016/j.susmat.2016.12.003.

Reshad, Ali Shemsedin, Pankaj Tiwari, and Vaibhav V. Goud. (2019) "Thermal and Co-Pyrolysis of Rubber Seed Cake with Waste Polystyrene for Bio-Oil Production." Journal of Analytical and Applied Pyrolysis 139: 333-43. https://doi.org/10.1016/j.jaap.2019.03.010.

Sanahuja-Parejo, O. et al. (2019) "Drop-in Biofuels from the Co-Pyrolysis of Grape Seeds and Polystyrene." Chemical Engineering Journa/377:120246. https://doi.org/10.1016/j.cej.2018.10.183

Shadangi, Krushna Prasad, and Kaustubha Mohanty. (2014) "Effect of Co-Pyrolysis of Mahua Seed and Waste Polystyrene on Quality of Liquid Fuel." 6: 053142. https://doi.org/10.1063/1.4900550

Shadangi, Krushna Prasad, and Kaustabha Mohanty. (2015) "Co-Pyrolysis of Karanja and Niger Seeds with Waste Polystyrene to Produce Liquid Fuel." Fuel 153: 492-98.

http://dx.doi.org/10.1016/j.fuel.2015.03.017

Somasundaram, Murugavelh, and Midhun Prasad k. (2019) "Co-Pyrolysis of Juliflora Biomass with LowDensity Polyethylene for Bio-Oil Synthesis." Energy Sources, Part A: Recovery, Utilization and Environmental Effects. https://doi.org/10.1080/15567036.2019.1635232

Stančin, H. et al. (2021) "Co-Pyrolysis and Synergistic Effect Analysis of Biomass Sawdust and Polystyrene Mixtures for Production of High-Quality Bio-Oils." Process Safety and Environmental Protection 145: 1-11. https://doi.org/10.1016/j.psep.2020.07.023

Suriapparao, Dadi V., Bhanupriya Boruah, Dharavath Raja, and R. Vinu. (2018) "Microwave Assisted CoPyrolysis of Biomasses with Polypropylene and Polystyrene for High Quality Bio-Oil Production." Fuel Processing Technology 175: 64-75. https://doi.org/10.1016/j.fuproc.2018.02.019.

Uzoejinwa, Benjamin Bernard et al. (2018) "Co-Pyrolysis of Biomass and Waste Plastics as a Thermochemical Conversion Technology for High-Grade Biofuel Production: Recent Progress and Future Directions Elsewhere Worldwide." Energy Conversion and Management 163(February): 468-92. https://doi.org/10.1016/j.enconman.2018.02.004.

Varma, Anil Kumar, and Prasenjit Mondal. (2016) "Parameters on Product Yields and Characterization of Products." Industrial Crops \& Products. http://dx.doi.org/10.1016/j.indcrop.2016.11.039. 
Vasu, Harvindran et al. (2019) "Insight into Co-Pyrolysis of Palm Kernel Shell (PKS) with Palm Oil Sludge (POS): Effect on Bio-Oil Yield and Properties." Waste and Biomass Valorization (0123456789).

https://doi.org/10.1007/s12649-019-00852-1.

Wang, Shurong, Dai, Gongxin, Yang, Haiping, and Luo, Zhongyang. (2017) "Lignocellulosic Biomass

Pyrolysis Mechanism: A State-of-the-Art Review." Progress in Energy and Combustion Science 62: 33-86. http://dx.doi.org/10.1016/j.pecs.2017.05.004.

Radhaboy, G, and Pugazhvadivu, M. (2020) "Properties of Bio-Oil Produced by Co-Pyrolysis of Calotropis Procera Stem and Waste Polystyrene." 2225: 040003(March). https://doi.org/10.1063/5.0006401

Zhang, Xuesong, Hanwu Lei, Shulin Chen, and Joan Wu. (2016) "Catalytic Co-Pyrolysis of Lignocellulosic Biomass with Polymers: A Critical Review." Green Chem. 18(15): 4145-69. http://xlink.rsc.org/? DOI=C6GC00911E.

\section{Figures}

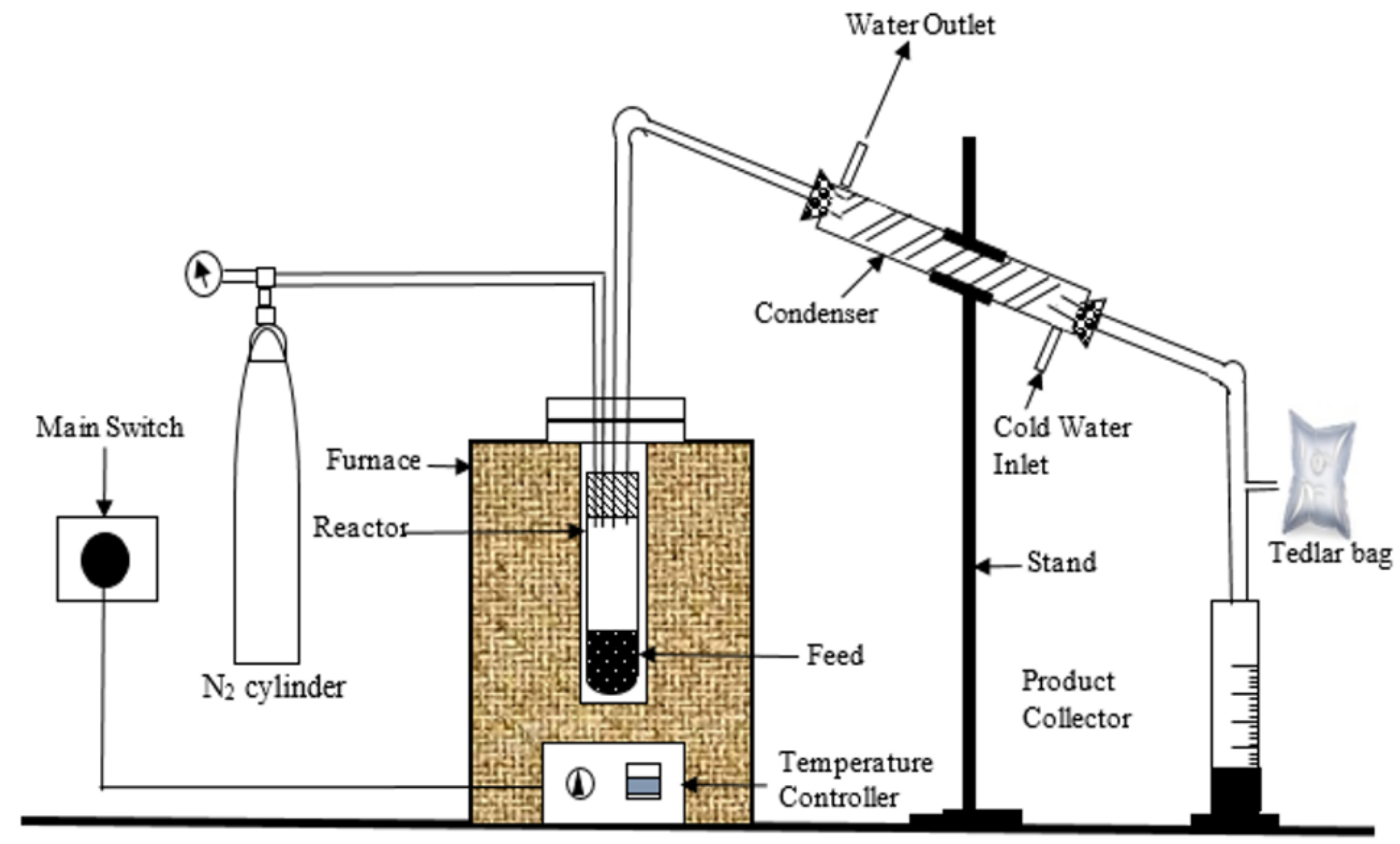

Figure 1

Pictorial presentation of the experimental setup 


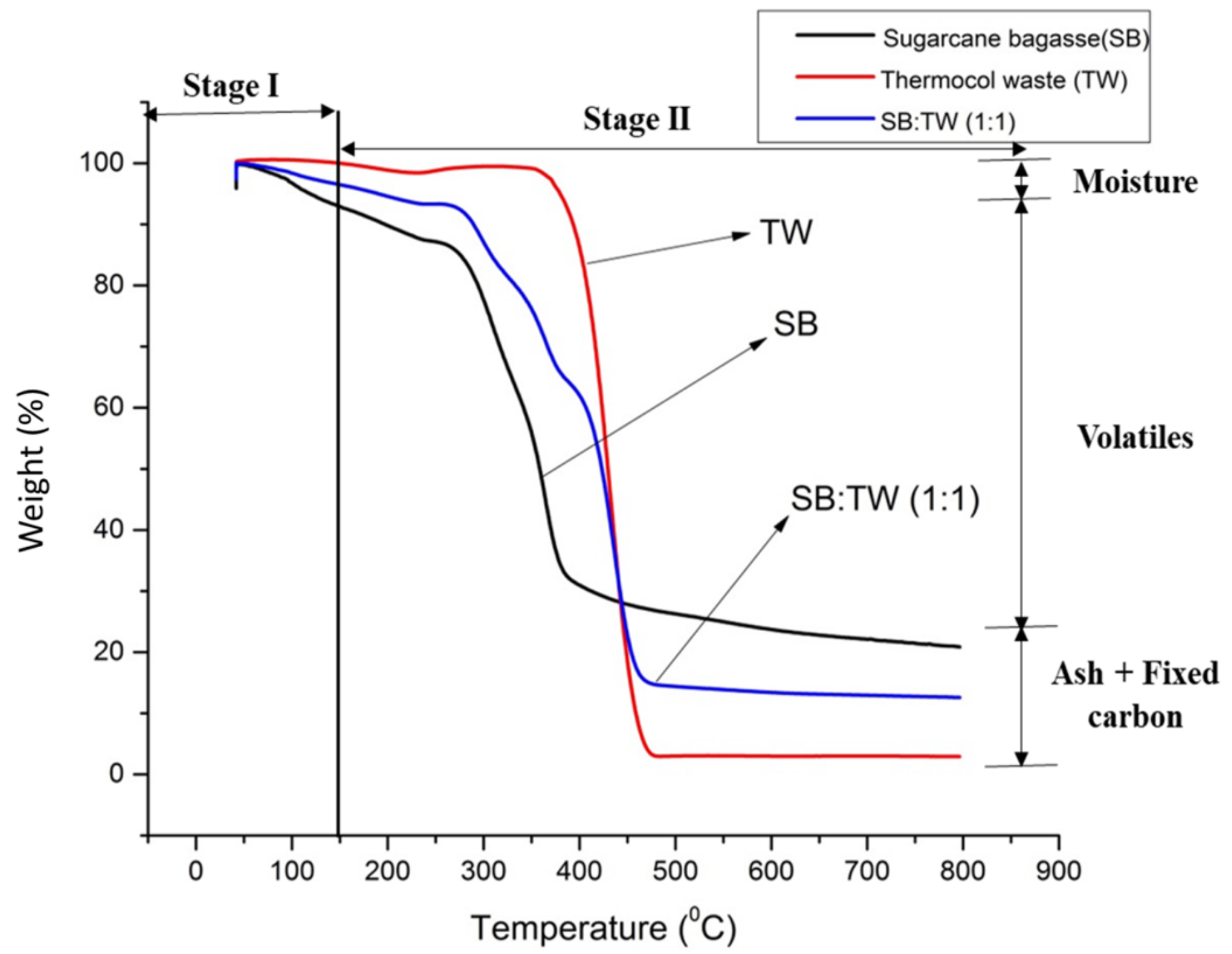

Figure 2

TGA thermogram of $\mathrm{SB}, \mathrm{TW}$ and $\mathrm{SB}$ :TW blend at 1:1 ratio 


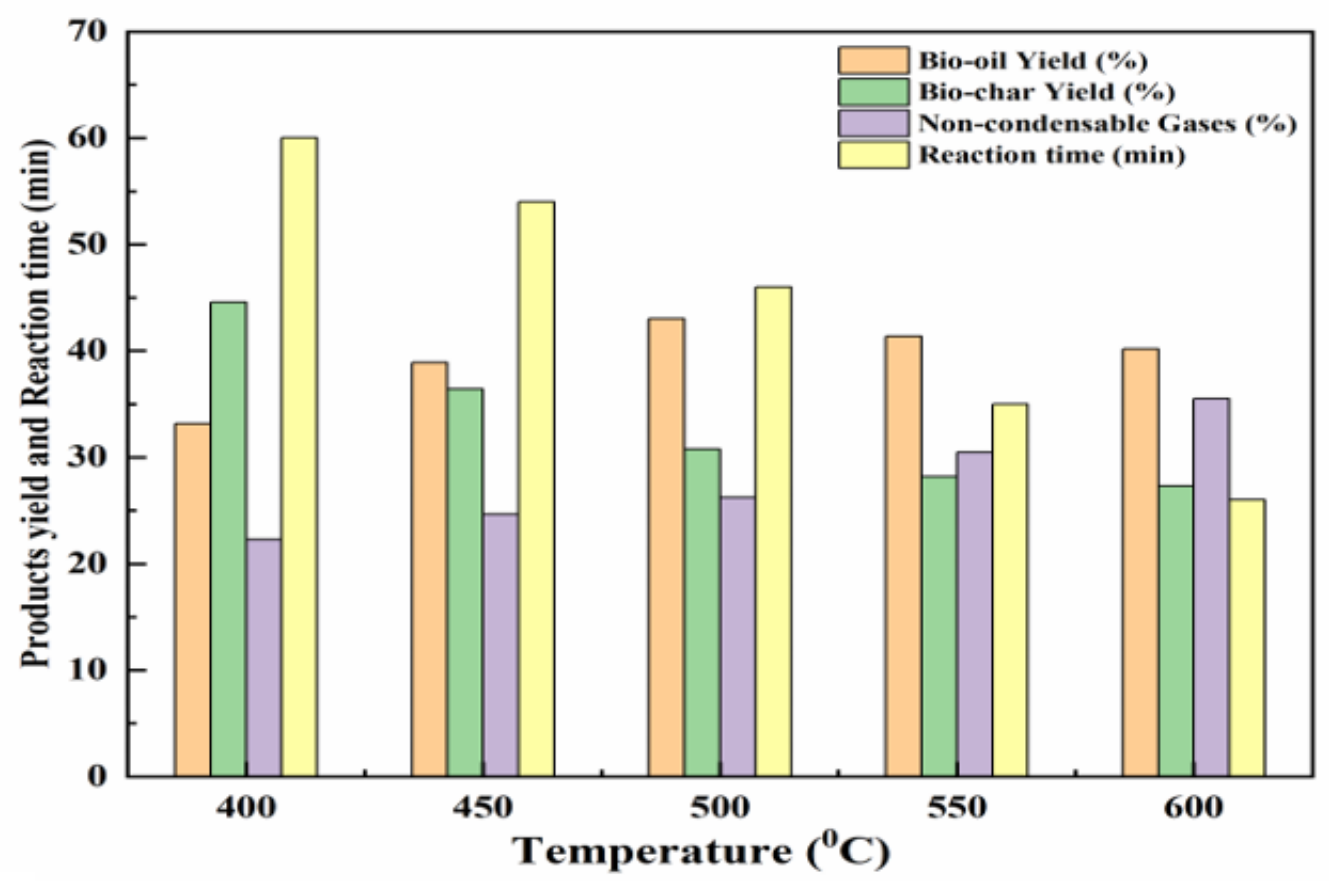

(a)

(b)

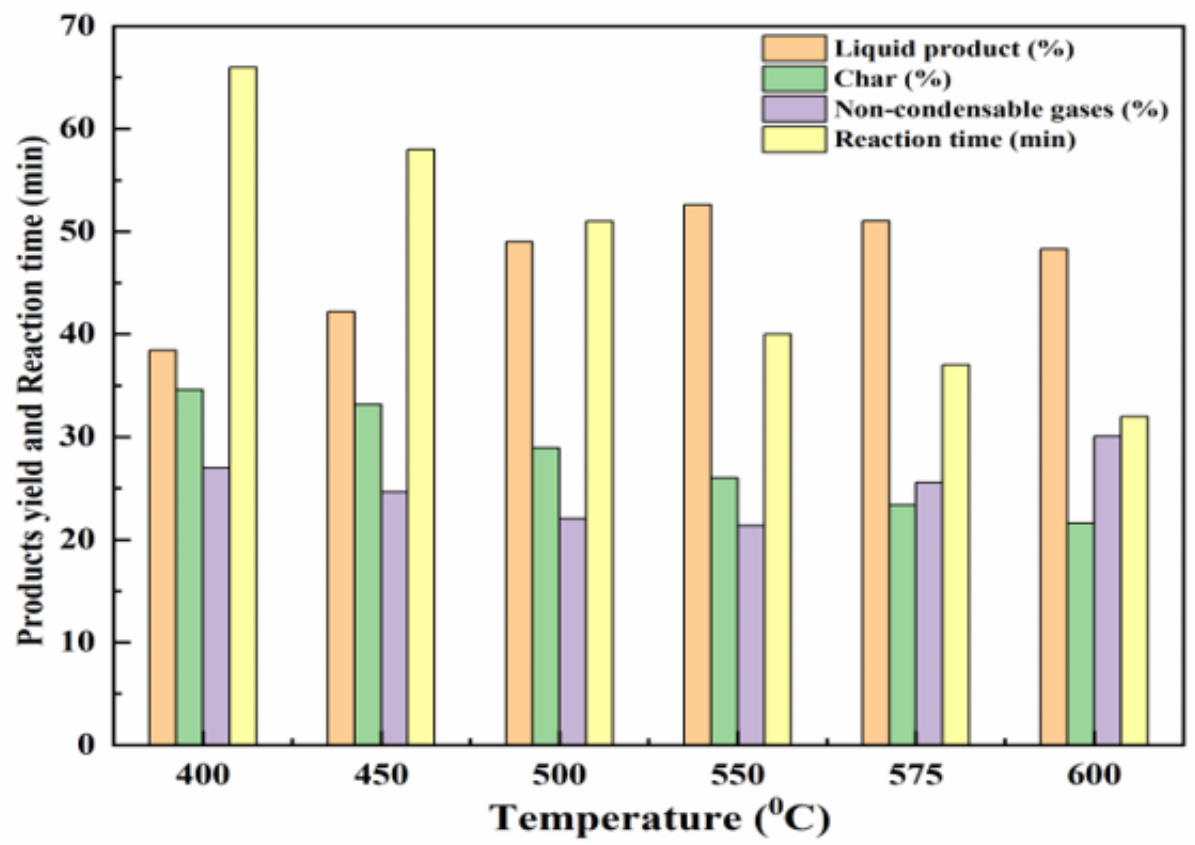

Figure 3

Effect of temperature on yields of various products and reaction time for (a) SB thermal pyrolysis, and (b) co-pyrolysis of SB and TW at 1:1 ratio 


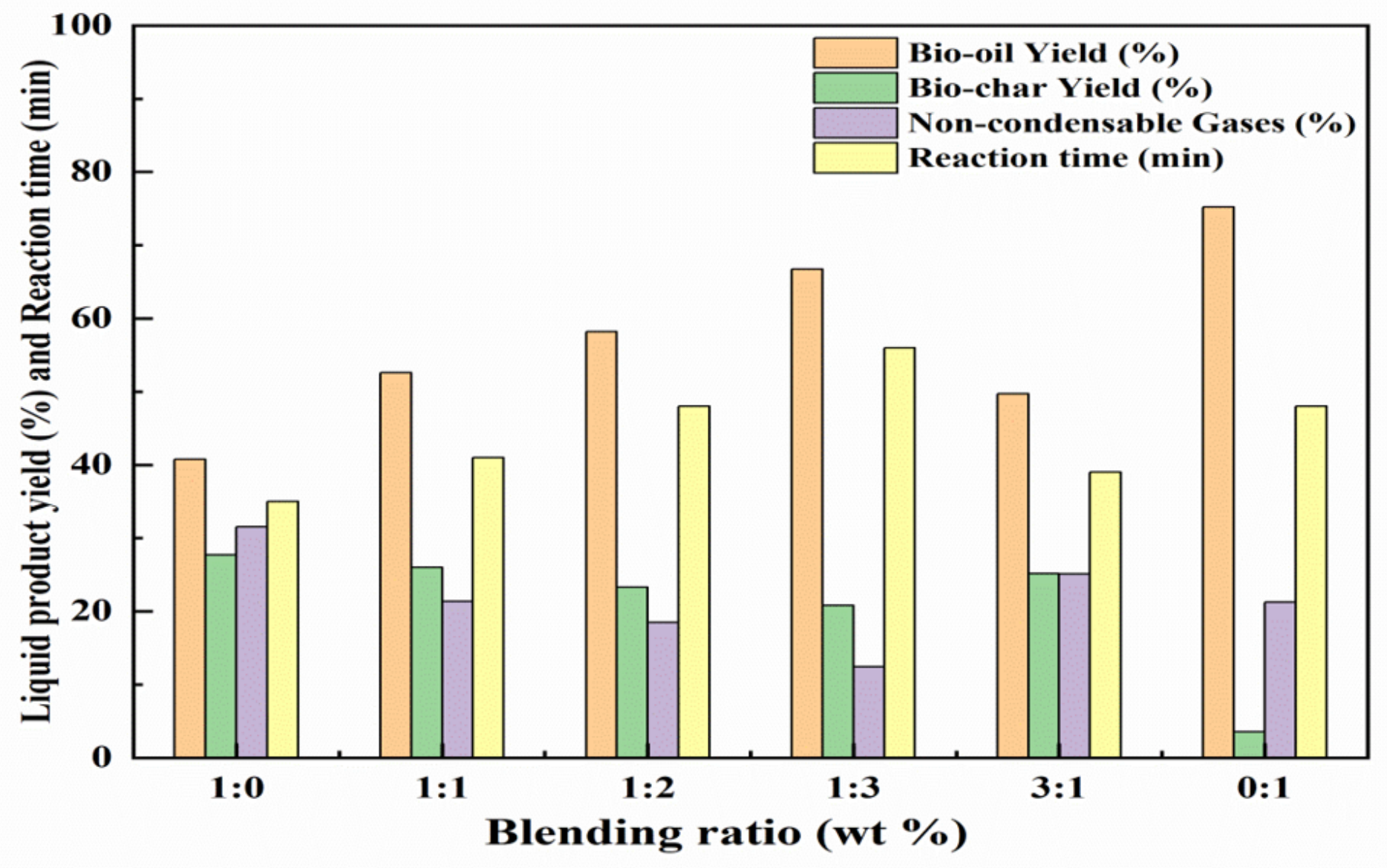

Figure 4

Effect of blending ratio of SB: TW on the yield of co-pyrolysis products at $550^{\circ} \mathrm{C}$ 


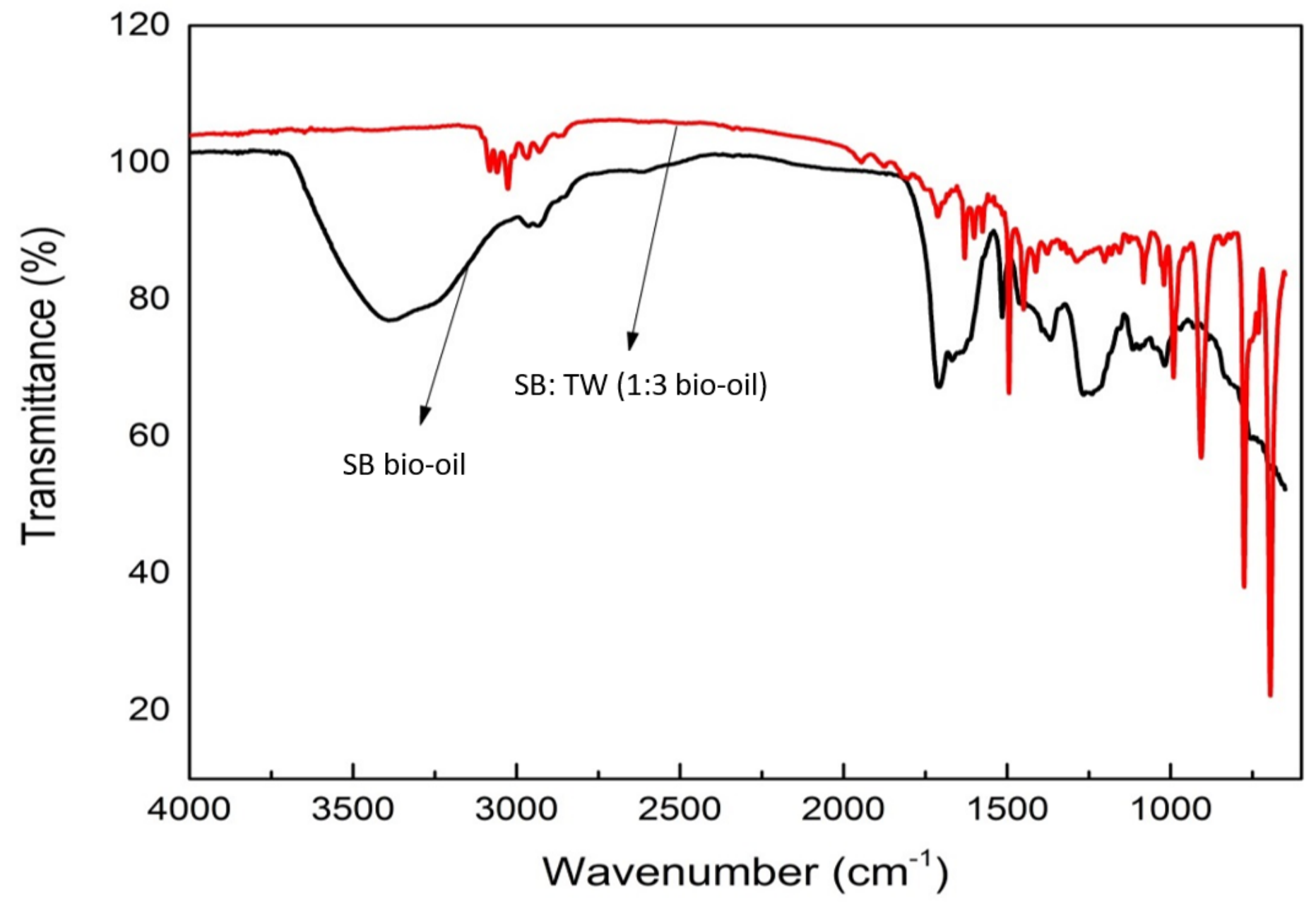

Figure 5

FT-IR spectra of SB bio-oil and SB: TW co-pyrolysis liquid product (Figure corrected) 


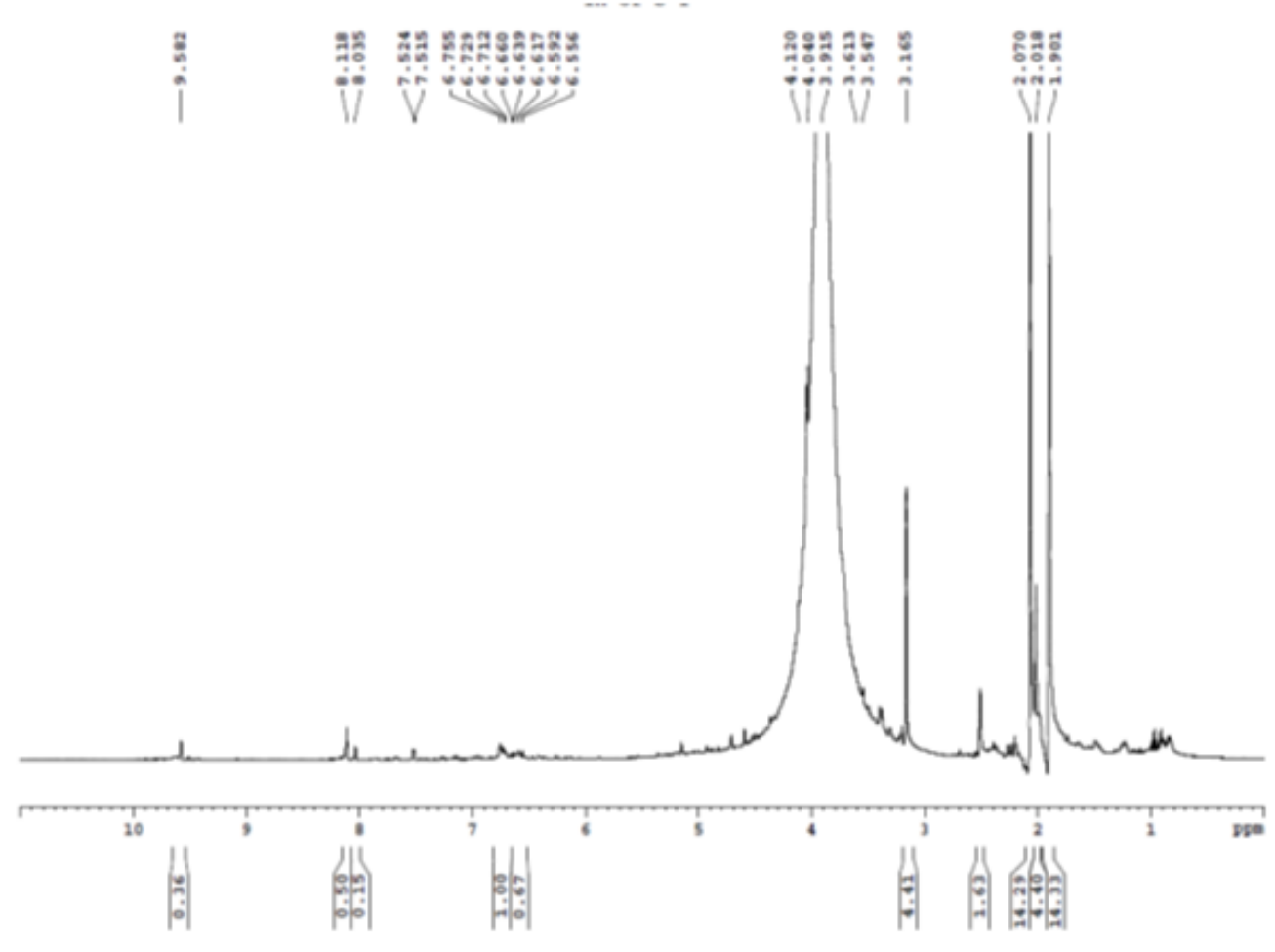

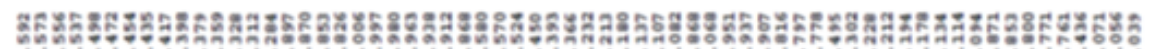
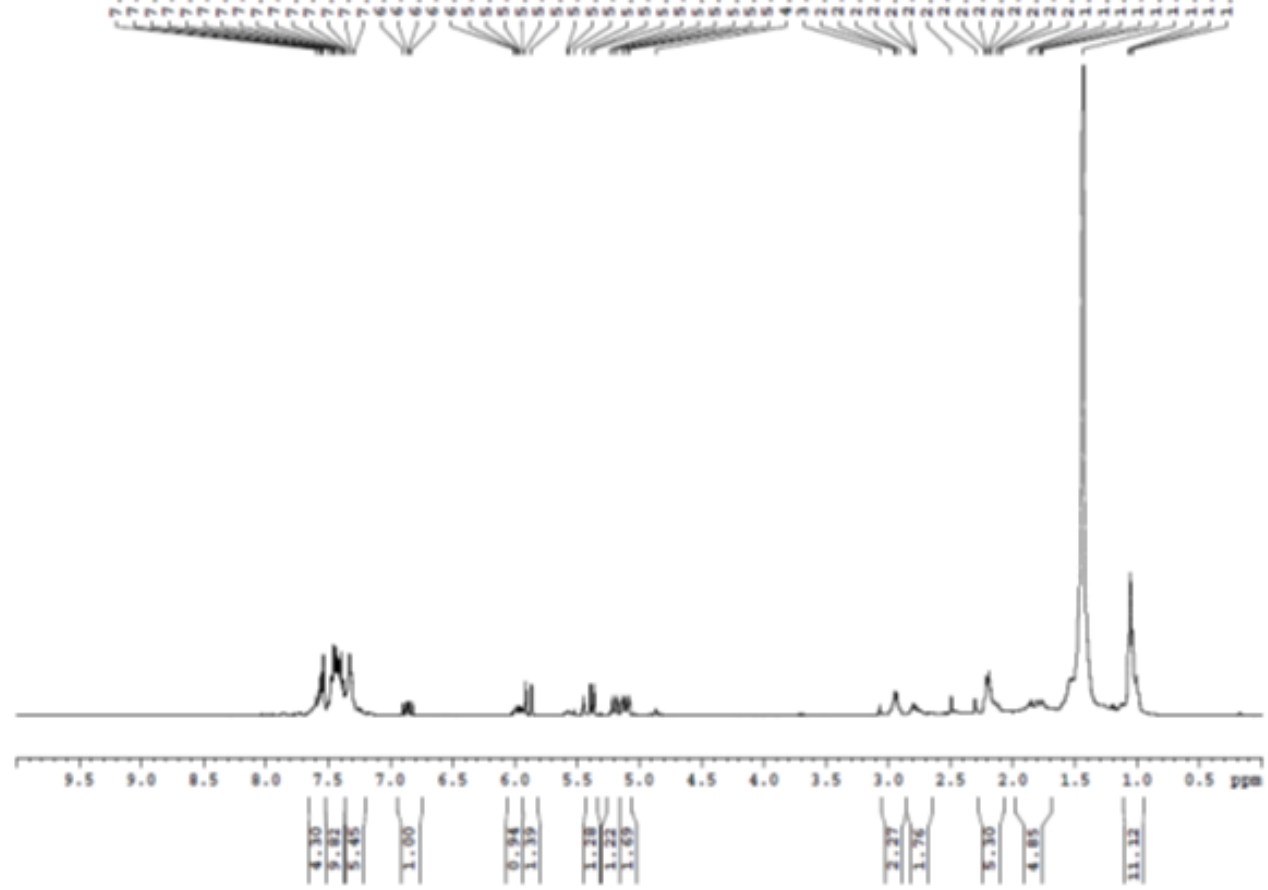

Figure 6

1H NMR spectrum of (a) SB bio-oil (b) SB: TW co-pyrolysis liquid product 


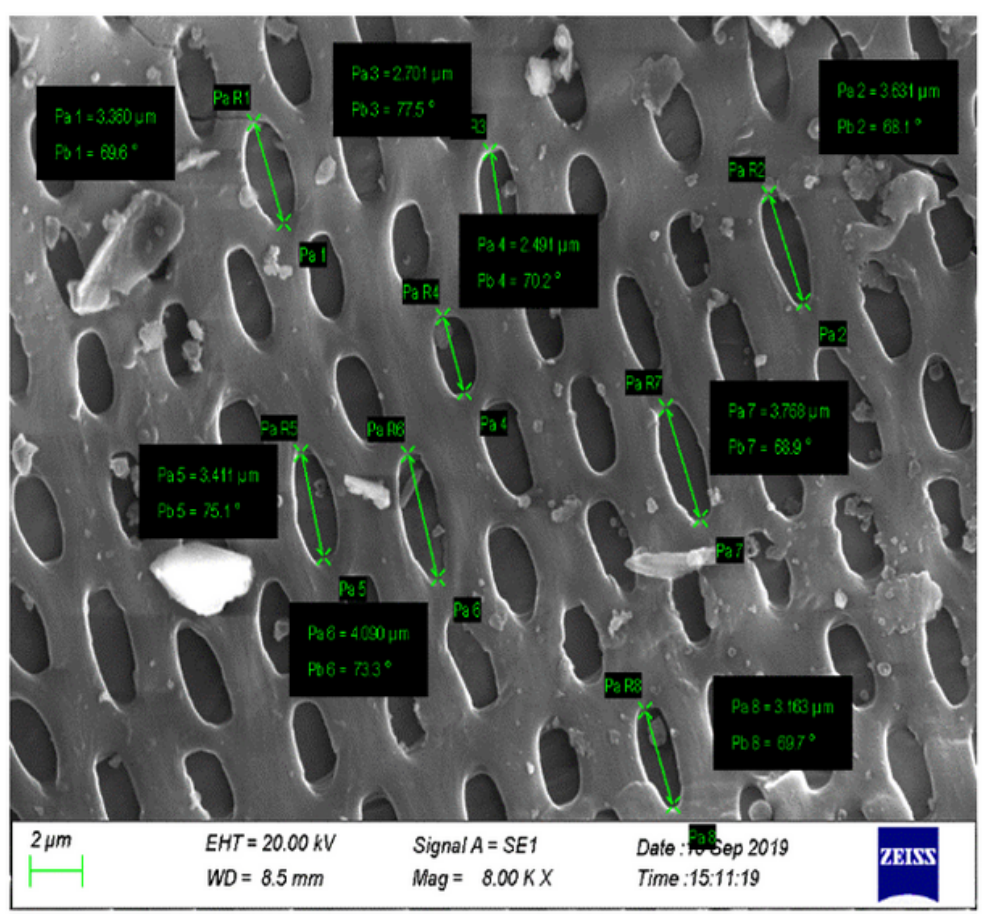

(a)

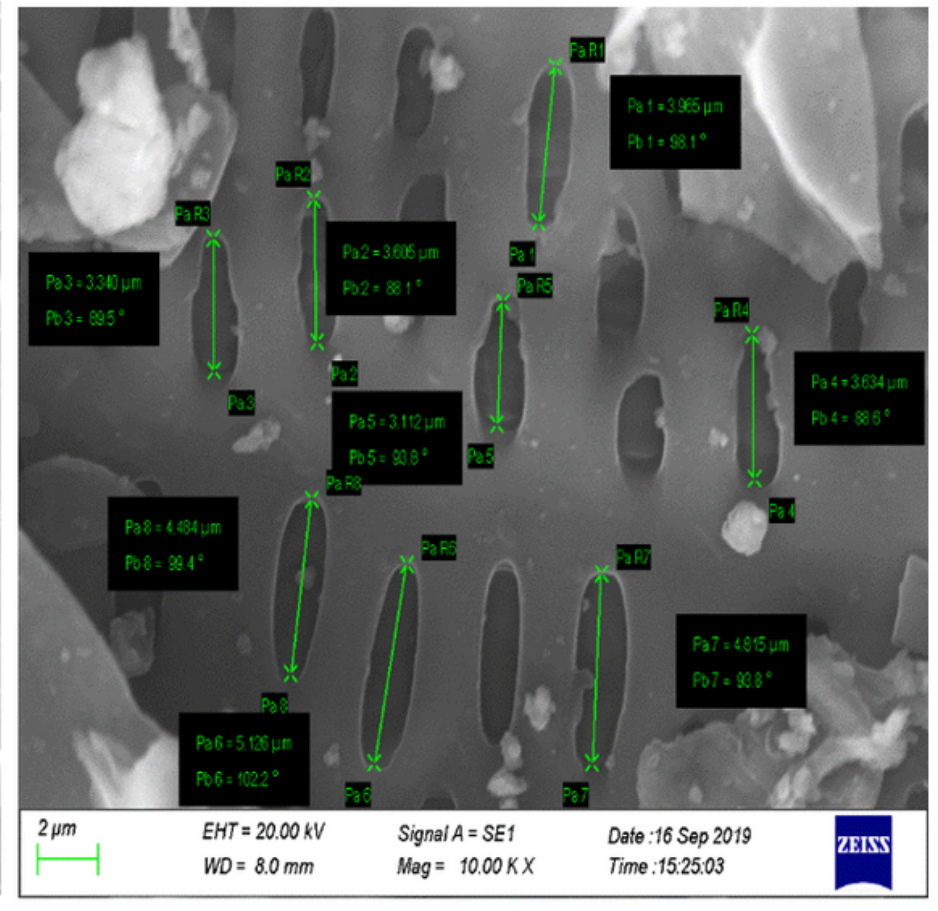

(b)

Figure 7

SEM micrographs of (a) SB bio-char (b) SB:TW bio-char 


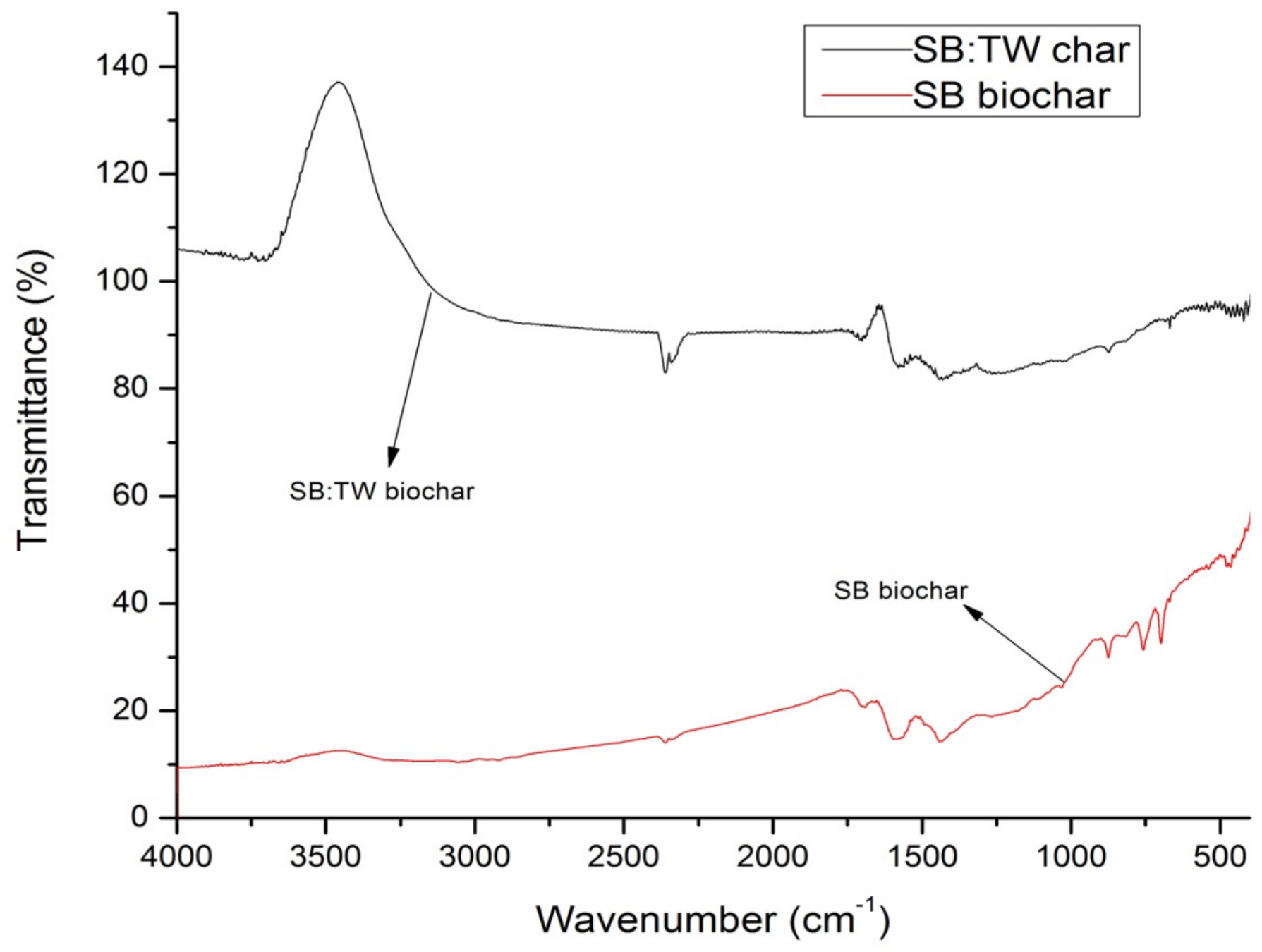

Figure 8

FT-IR spectra of SB and SB: TW biochar 